\title{
Racismo algorítmico: uma análise da branquitude nos bancos de imagens digitais
}

\author{
Algorithmic racism: an analysis of whitness in digital stock images
}

\author{
Augusto Jobim do Amaral \\ Fernanda Martins ${ }^{* *}$ \\ Ana Clara Elesbão
}

\section{Resumo}

\begin{abstract}
Diante do novo contexto sociotécnico em que algoritmos e dados configuram novas formas de controle social, a pesquisa propõe-se a investigar o modo como sistemas informáticos em rede têm servido como método multifacetado de categorização e classificação social. Assim, este trabalho tem como objetivo explorar a temática dos algoritmos em bancos de imagens digitais, buscando compreender de que maneira tais tecnologias produzem resultados racistas. A metodologia de pesquisa empregada consiste basicamente na análise dos resultados oferecidos pelos bancos de imagens escolhidos (Getty Images, Shutterstock e Stockphotos) para a busca por uma palavra-chave genérica (family), no intuito de observar o modo como os resultados são racializados pelos algoritmos de busca. Os resultados indicam que o conteúdo oferecido pelos bancos de imagens costuma ser racializados, privilegiando a representação da branquitude como lugar de centralidade que reduz a multiplicidade de subjetividades e existências, traduzindo-se como significante universal. Assim, em termos exploratórios, é possível afirmar que os processos e rotinas produtivas mediadas por algoritmos cumprem, em larga medida, um papel fundamental na produção de resultados racistas nos bancos de imagens analisados.
\end{abstract}

Palavras-chave: Algoritmos. Inteligência artificial. Bancos de imagens. Branquitude. Racismo.

\section{Abstract}

Due to the new socio-technical context in which algorithms and data configure new forms of social control, the research proposes investigating how networked computer systems have served as a multifaceted method of social categorization and classification. Thus, this work aims to explore the theme of algorithms in digital image banks, seeking to understand how such technologies produce racist results. The research methodology consists of analyzing the results offered by the chosen image banks (Getty Images, Shutterstock, and Stockphotos) to search for a generic keyword ("family"), to observe how the results are racialized by search algorithms. The results indicate that the content offered by image banks is usually racialized, privileging the representation of whiteness as a place of centrality that reduces the multiplicity of subjectivities and existences, translating itself as a universal signifier. In exploratory terms, it is possible to affirm that the productive processes and routines mediated by algorithms play, to a large extent, a fundamental role in the production of racist results in the analyzed image banks.

Keywords: Algorithms. Artificial Intelligence. Image Banks. Whiteness. Racism.

\section{Introdução}

O uso cada vez mais expressivo de novas tecnologias digitais tem colocado questões importantes no tocante ao seu modo de funcionamento, apresentando desafios no sentido de compreender as relações entre tecnologia,

* (9) Doutor em Altos Estudos Contemporâneos (Ciência Política, História das Ideias e Estudos Internacionais Comparativos) pela Universidade de Coimbra (Portugal); Doutor, Mestre e Especialista em Ciências Criminais pela Pontifícia Universidade Católica do Rio Grande do Sul (PUCRS). Possui graduação em Ciências Jurídicas e Sociais pela Pontifícia Universidade Católica do Rio Grande do Sul (PUCRS) e Pós-Graduação em Direito Penal Econômico e Europeu pela Universidade de Coimbra. É Professor do Programa de Pós-graduação em Ciências Criminais (PPGCCrim) da Pontifícia Universidade Católica do Rio Grande do Sul (PUCRS) junto à linha de Criminologia, Crime e Segurança Pública. Pesquisador-convidado do lus Gentium Conimbrigae (IGC) - Centro de Direitos Humanos da Universidade de Coimbra, tendo experiência na área de Direito e História das Ideias, com ênfase em Criminologia, Direitos Humanos, Direito Penal e Processo Penal, Filosofia e Sociologia do Direito. Atua, principalmente, nos seguintes temas: cultura penal, violência punitiva, direitos humanos; controle social e segurança pública; sociologia e filosofia políticas; criminologia, direito penal e processo penal. E-mail: guto_jobim@hotmail.com

Doutora em Ciências Criminais pela Pontifícia Universidade Católica do Rio Grande do Sul (PUCRS). Mestre em Direito pela Universidade do Vale do Itajaí (UNIVALI). Graduada em História pela Universidade Federal de Santa Catarina (UFSC) e Ciências Jurídicas e Sociais (UNIVALI). E-mail: fernanda.ma@gmail.com.

(9) Mestranda em Ciências Criminais pela Pontifícia Universidade Católica do Rio Grande do Sul (PUCRS) com bolsa CAPES. E-mail: anaelesbaos@ gmail.com. 
poder e política. Tal compromisso passa por investigar de que maneira a tecnologia insere-se nos regimes de exercício de poder, reconfigurando práticas de proibição, prescrição e regulação de condutas, bem como forjando novos processos de subjetivação no que se poderia chamar de governamentalidade algorítmica (ROUVROY; BERNS, 2015). Este trabalho insere-se nessa perspectiva, com o objetivo precípuo de interrogar os dispositivos digitais de decisão automatizada, em especial os algoritmos de busca e seleção de conteúdo em bancos de imagens.

Estudos recentes acerca da temática têm constatado vieses raciais nos resultados produzidos por esses bancos de imagens. A pesquisa descrita no artigo Algoritmos racistas: uma análise da hiper-ritualização da mulher negra em bancos de imagens digitais (CARRERA; CARVALHO, 2019), publicado nos Anais do XXVIII Encontro Anual da Associação Nacional dos Programas de Pós-Graduação em Comunicação (Compós), demonstrou que o conteúdo apresentado por três bancos de imagens para a busca por determinadas palavras-chave expressa conexões discriminatórias associadas a marcadores de raça e gênero.

Este artigo apresenta os resultados da pesquisa digital exploratória que buscou analisar o conteúdo resultante dos algoritmos de busca em bancos de imagens (Getty Images, Shutterstock e Stockphotos) para a busca pela palavra-chave family. A pesquisa consiste em um levantamento capaz de analisar o modo como os resultados para determinada palavra-chave genérica são racializados algoritmicamente. A metodologia empregada foi desenhada de modo a que seus resultados fossem comparáveis segundo a pesquisa Algoritmos racistas: uma análise da hiper-ritualização da mulher negra em bancos de imagens digitais, mencionada anteriormente e realizada em 2019. A análise comparativa ateve-se, principalmente, a eventos particulares durante o período em que a pesquisa foi realizada, a partir de reações de dois dos bancos de imagens analisados à emergencia do movimiento Black Lives Matter e ao apelo à representatividade negra nesse contexto.

\section{Racismos digitalizados}

Desde o conteúdo das comunicações que circulam na rede mundial de computadores, passando pelo modus operandi dos algoritmos de processamento de dados, até as condições materiais de trabalho nas grandes corporações de mídias digitais, a gama de novas tecnologias computo-informacionais atua no ajustamento entre certa governamentalidade neoliberal ${ }^{1}$ e suas necessidades de atualização e de expansão. Nesse sentido, tais tecnologias colocam em circulação um determinado discurso sobre as técnicas que não cessa de se realizar, na medida em que as organiza em um sistema rentável voltado para o progresso, mensurado pela medida do produtivismo (COMITÊ INVISÍVEL, 2015).

A constatação de certo processo de saturação da lógica centrada num dispositivo geral de governamentalidade - tal como instalado em meados do século XVIII (AMARAL, 2020) - parece convergir com o alerta feito por Deleuze (1992, p. 219-226) em seu Post-scriptum sobre sociedades de controle, texto em que retomou a análise das tecnologias de poder desde um horizonte foucaultiano, apontando, no cruzamento entre elas, a proeminência do controle ${ }^{2}$ em detrimento dos aspectos disciplinares, "cuja crise todo mundo anuncia[va]" (DELEUZE, 1992, p. 225). Quase trinta anos após a publicação desse texto, o dispositivo geral de governamentalidade, centrado nos meios de confinamento disciplinares, parece ceder cada vez mais espaço a uma nova forma de governação progressivamente mais aproximada dos regimes de controle. Sua lógica dispersa baseia-se em um processo metaestável de modulação contínua em que os estados fazem referência a um mesmo deformador universal (DELEUZE, 1992, p. 221).

1 As políticas neoliberais ensaiadas pelos governos de Margareth Tatcher e Ronald Reagan durante os anos 1980 simbolizaram um rompimento histórico com a social-democracia e a implementação de novas políticas que supostamente poderiam superar a crise econômica e social do regime fordista de acumulação de capital (DARDOT\& LAVAL, 2016, p. 189). Essas políticas revelaram mudanças fundamentais no funcionamento do capitalismo, ligadas ao surgimento de um novo modo de exercício do poder governamental; de uma nova racionalidade política e social articulada à globalização e à financeirização do capital (p. 190). Trata-se, em última análise, de uma racionalidade governamental, que tende a conduzir não só a ação dos governantes como a conduta dos governados; uma governamentalidade que se exerce transversalmente segundo uma lógica normativa global generalizada, que tem a concorrência como norma de conduta e a empresa como modelo de Estado e também de subjetivação (pp. 17 e 397). Essa concepção, desenvolvida recentemente por Pierre Dardot e Christian Laval, parte, naturalmente, de um horizonte foucaultiano com o qual dialogamos em profundidade para pensar as questões que movem este trabalho de pesquisa. Essas noções foram largamente desenvolvidas em pelo menos dois seminários ministrados por Foucault, em que explorou especialmente suas concepções de biopoder e de biopolítica. São eles: FOUCAULT, 2008a, e FOUCAULT, 2008b. É nesse sentido a que nos referimos ao neoliberalismo neste trabalho; como um regime particular de exercício de poder que estabelece os paradigmas hegemônicos de relação.

2 Deleuze chamou de sociedades de controle o que descreveu como "novas forças que se anunciam", em substituição às sociedades disciplinares descritas por Foucault. "'Controle' é o nome que Burroughs propõe para designar o novo monstro, e que Foucault reconhece como nosso futuro próximo" (DELEUZE, 1992, p. 220). Tal como descritos por Deleuze, pode ser entendido como parte de um regime que dá continuidade ao governo como tecnologia de poder em proeminência, mas rearticulado segundo novos instrumentos e modos de atuação. 
Para que circule desse modo, o controle não se exerce mais sobre o par massa-indivíduo: transforma os indivíduos em "dividuais", isto é, divisíveis em dados; e as massas em bancos e amostras compostos por montantes desses dados (DELEUZE, 1992, p. 222). Assim, a operacionalidade do controle tem se tornado possível graças ao desenvolvimento de computadores, máquinas informáticas e tecnologias digitais de comunicação e circulação de informações, que funcionam segundo uma linguagem numérica cifrada pretensamente universal (DREYFUS, 1979, p. 33). Essas características propiciaram o surgimento de novas oportunidades de agregação, análise e correlações estatísticas de dados (ROUVROY; BERNS, 2015, p. 37) sem as quais não seria viável compreendê-los e manejá-los no nível das populações.

Não por acaso, o que toda a gama de tecnologias computo-informacionais tem em comum é a capacidade de coletar, armazenar, analisar e correlacionar quantidades massivas de dados e metadados gerados a partir das comunicações e das atividades dos "usuários" - tanto naquilo que se poderia chamar de um espaço on-line quanto offline, dissipando cada vez mais uma suposta fronteira entre tais experiências. Esses bancos gigantescos de dados, formados a partir dos mais variados mecanismos de coleta, são processados por algoritmos, isto é, diagramas de instruções codificadas em linguagem numérica, cujo objetivo é produzir respostas que correspondam a determinados objetivos colocados (O'NEIL, 2016). Assim, os algoritmos situam-se no cruzamento multifatorial de vetores que tensionam relações, regendo os métodos e determinando a operacionalidade dos regimes de controle vigentes.

É precisamente nesse sentido que podemos afirmar estarmos diante de uma governamentalidade algorítmica, isto é, uma racionalidade pretensamente "objetiva", "que repousa sobre a coleta, a agregação e a análise automatizada de dados em quantidade massiva de modo a modelizar, antecipar e afetar, por antecipação, os comportamentos possíveis"(ROUVROY; BERNS, 2015, p. 42). Condicionando o horizonte de possibilidades com base em projeções de padrões, os algoritmos dissipam as condições espaciais, temporais e linguísticas da subjetivação e da individuação em benefício de uma regulação objetiva e operacional das condutas possíveis que atua na realidade, produzindo o social e suas significações sem mediação significante (ROUVROY; BERNS, 2015, p. 44).

O resultado é que, se permanecermos numa perspectiva individualista, liberal, a ação sobre os comportamentos, o que nós chamamos "governo algorítmico", aparece, ao mesmo tempo, como fundamentalmente inofensiva e como perfeitamente objetiva, posto que fundada sobre uma realidade anterior a toda manifestação de entendimento ou de vontade subjetivos, individuais ou coletivos, uma realidade que, paradoxalmente, parece tanto mais confiável e objetiva quanto mais ela provoca a abstração de nosso entendimento, mas alimentando o sonho de um governo perfeitamente democrático.

Nesse sentido, é fundamental compreender as tensões que perpassam tais práticas e que forjam suas linhas de força. Para tanto, parece-nos elementar perceber de que modo subjetividades são dissipadas ou anuladas por uma moldura técnica predefinida desde uma expectativa de gênero, sexualidade, raça e tantos outros delineadores normativos (ROUVROY; BERNS, 2015, p. 55).

\subsection{Algoritmos racializados}

Conforme o exposto, a circulação dos regimes de controle contínuo reconfigura a circulação de poder e as práticas de subjetivação, devendo ensejar o estudo sociotécnico de seus modos de funcionamento (DELEUZE, 1992, p. 125) para além das margens de um paradigma liberal. Nesse objetivo, pode-se destacar o surgimento dos chamados Science and Technology Studies (Estudos sobre Ciência e Tecnologia, em português), em meados da década de 1970. Esse campo de estudos é precursor na abordagem do desenvolvimento científico e tecnológico através de redes sociotécnicas complexas de relações sujeitas a tensionamentos multidirecionais (cf. LATOUR, 2000; 2012). No entanto, apesar do salto significativo que promoveram no tratamento do tema - insistindo nas dimensões políticas, econômicas e sociais das tecnologias -, muito ainda há por identificar sobre como essas redes são atravessadas e constituídas por práticas discriminatórias, racializadas e generificadas (NOBLE, 2016).

Neste sentido, segundo Noble (2016), uma abordagem feminista interseccional ${ }^{3}$ para os estudos digitais oferece um ponto de partida para pensarmos as relações de poder que constituem os sistemas e infraestruturas globais de comunicação e circulação de informações, bem como aspectos de vigilância e de controle. Tal enfoque implica

3 Interseccionalidade é um conceito de Kimberlé Crenshaw que busca construir uma observação analítica que explore "vários sentidos pelos quais raça e gênero se cruzam para moldar os aspectos estruturais, políticos e representacionais da violência contra mulheres não brancas" (CRENSHAW 1989; 1991). 
compreender que esses dispositivos não são apenas locais universais de acesso, tampouco são disponibilizados de forma igual e equitativa. Ao contrário, estão inseridos em relações de poder que recaem diferentemente sobre corpos atravessados por inúmeros marcadores entre os quais raça, classe e gênero são alguns exemplos.

Diante desse contexto, nos últimos anos, diversas pesquisas têm examinado os fenômenos da tecnologia digital buscando perceber de que maneira os dispositivos digitais de controle interagem com marcadores sociais criando condições de exposição desigual a situações discriminatórias (DONEDA, MENDES; SOUZA; ANDRADE, 2018, p. 3-6). Nos países colonizados, em especial o Brasil, assinalar o sentido desta compreensão passa por pensar nos processos racistas da constituição de subjetividades. Trata-se de um "recorte" imperioso para qualquer reflexão responsável e interessada na gravidade das experiências constituídas em terras brasileiras.

Nessa perspectiva, Tarcízio Silva defende a importância dos estudos sobre branquitude ${ }^{4}$ como uma chave importante para compreender os modos pelos quais as tecnologias automatizadas demonstram continuamente vieses racistas (SILVA, 2020). Isso porque, segundo o pesquisador, a Ciência e a Tecnologia cumprem um papel de destaque na manutenção e na reprodução dos privilégios dessa branquitude, implicando uma "dupla opacidade" demarcada pelo modo como "os discursos hegemônicos invisibilizam tanto os aspectos sociais da tecnologia quanto os debates sobre a primazia de questões raciais nas diversas esferas da sociedade - incluindo a tecnologia, recursivamente" (SILVA, 2020, 432).

É nesse sentido que, quando falamos em discriminação nos meios digitais, torna-se necessário atentar aos modos pelos quais tais dispositivos reproduzem estes traços em sua operacionalidade ordinária. É o caso do mecanismo de funcionamento dos chamados "algoritmos de relevância pública", cuja análise dedicamos este trabalho de pesquisa. Esse conceito foi cunhado por Tarleton Gillespie, no âmbito dos Estudos sobre Ciência e Tecnologia, designando os algoritmos utilizados para determinar a visibilidade de conteúdos num determinado ecossistema informacional (GILLESPIE, 2018, p. 97).

\subsubsection{Algoritmos de relevância pública em bancos de imagens}

Algoritmos, no âmbito computo-informacional, são sequências de comandos codificados em linguagem numérica que servem para transformar dados em resultados desejados a partir de decisões automatizadas (GILLESPIE, 2018). Trata-se de diagramas organizados em rotinas procedimentais que podem ser descritas genérica e ilustrativamente em pelo menos três etapas: (a) coleta de quantidade massiva de dados e constituição de data werehouses; (b) tratamento de dados e produção de conhecimento; (c) ação sobre comportamentos (GILLESPIE, 2018).

Os algoritmos têm sido utilizados para a execução das mais diversas funções em procedimentos computo-informacionais, atuando na articulação entre dispositivos de vigilância e de modulação de dados. Neste trabalho de pesquisa, interessa-nos em especial os chamados "algoritmos de relevância pública" (GILLESPIE, 2018), utilizados para determinar a visibilidade de conteúdos em plataformas de mídias sociais, mecanismos de busca, sistemas de recomendação e bases de dados. Sua função consiste em selecionar qual conteúdo deve ser considerado mais relevante para que seja apresentado de forma prioritária ao usuário em determinado contexto (JURNO, 2018, p. 20). Tal seleção é feita segundo rotinas de programação utilizadas para avaliar os conteúdos com base em lógicas particulares de preparação, categorização, classificação e correlação dos dados disponíveis.

De acordo com Amanda Jurno, esses algoritmos instauram uma lógica própria de administração dos fluxos de informações, uma vez que reorganizam os conteúdos com a finalidade de contemplar aquilo que detectam como sendo de interesse de cada um, instaurando um regime particular de visibilidade e invisibilidade (JURNO, 2018). Dessa forma, participam da constituição do debate público e da construção do imaginário social, na medida em que implementam um novo regime de circulação de informações. Para mencionar alguns exemplos bastante populares, lembramos do conjunto de algoritmos que selecionam os posts que devem aparecer de forma prioritária

4 De acordo com Maria Aparecida Bento, a branquitude pode ser entendida como "um lugar de privilégio racial, econômico e político, no qual a racialidade, não nomeada como tal, carregada de valores, de experiências, de identificações afetivas, acaba por definir a sociedade. Branquitude como preservação de hierarquias raciais, como pacto entre iguais, encontra um território particularmente fecundo nas Organizações, as quais são essencialmente reprodutoras e conservadoras" (BENTO, 2002, p. 7). O racismo cumpre papel central nesses processos. Nesse sentido, lembranos Grada Kilomba: “No racismo, corpos negros são construídos como corpos impróprios, como corpos que estão 'fora do lugar' e, por essa razão, corpos que não podem pertencer. Corpos brancos, ao contrário, são construídos como próprios, são corpos que estão 'no lugar', 'em casa', corpos que sempre pertencem" (KILOMBA, 2020, p. 39). 
no feed de notícias ${ }^{5}$ de um usuário do Facebook, ou aqueles que realizam o ranqueamento de sites que devem aparecer na primeira página do Google Search para uma busca informada por palavras-chave.

No entanto, apesar da expressiva importância desses dispositivos para a reconfiguração do que se poderia considerar espaço público, os procedimentos de decisão automatizada ocorrem no interior de "caixas-pretas" (PASQUALE, 2015) que ocultam seus mecanismos de funcionamento desde a coleta dos dados até a produção dos resultados entregues aos "usuários". Além disso, o aprimoramento desses dispositivos inclui a entrega de conteúdos cada vez mais personalizados ao "perfil" de cada "usuário". Esse aspecto de personalização dos resultados contribui para uma fragmentação da percepção do espaço público, e para uma colonização desse espaço por uma esfera privada de filtragem que leva a formas de imunizações informacionais nocivas à experiência comum (ROUVROY; BERNS, 2015).

Diante disso, destaca-se a falta de acesso a informações sobre os critérios utilizados pelas plataformas na produção dos resultados oferecidos. Nesse aspecto, Noble destaca a importância de pensarmos como os resultados aparecem, para que possamos, a partir deles, revelar alguns dos processos envolvidos em sua produção (NOBLE, 2018, p. 31). Assim, diversas pesquisas têm buscado analisar os resultados oferecidos por algoritmos de relevância pública para extrair deles aquilo que podem revelar sobre o modo como foram produzidos (CARRERA, 2020; CARRERA e CARVALHO, 2019; JURNO, 2019; NOBLE, 2013; NOBLE, 2018; TUFEKCI, 2015).

A partir desse princípio de investigação, buscamos analisar os resultados produzidos por algoritmos de relevância pública utilizados por bancos de imagens, ou seja, repositórios de fotografias, ilustrações, vetores e desenhos gráficos que servem como importantes fontes para o mercado publicitário na produção de conteúdo digital, como propagandas, sites e blogs privados e até mesmo governamentais (CARRERA, 2020). Esses bancos de imagens funcionam como um mecanismo de busca que seleciona e ranqueia as imagens a serem apresentadas quando pesquisada uma determinada palavra-chave. Assim, através do mecanismo de busca e do uso de filtros e categorias, é possível encontrar imagens adequadas à necessidade do profissional, uma vez que, em geral, cada busca gera dezenas de páginas e milhares de resultados considerados "relevantes" (CARRERA, 2020, p. 140).

Fernanda Carrera explica o modo como as imagens são indexadas e colocadas em circulação pelos mecanismos de busca desses bancos de imagens: o material é disponibilizado por fotógrafos - independentes ou associados ao site - de acordo com seu acervo ou sob demandas específicas. No momento de realizar o upload do material, o próprio fotógrafo cria tags (etiquetas de marcação) para cada documento, oferecendo uma interpretação ao conteúdo representado pelas imagens, bem como a associação a possíveis palavras-chave. Posteriormente, o banco de imagens revisa o tagueamento realizado e coloca o material à disposição no site (CARRERA, 2020, p. 141).

Esse processo de tagueamento é uma pista importante sobre o modo de funcionamento dos mecanismos de busca, mas é importante lembrar que há um processo algorítmico pouco transparente. Segundo Fernanda Carrera, não é possível afirmar se há ou não outros constructos operacionais para além do tagueamento que atribuem relevância à determinada imagem em detrimento de outras. Além disso, "não há certeza se esse processo se baseia apenas em um processo de reconhecimento de padrões ou também é fruto de certos parâmetros de machine learning" (CARRERA, 2020, p. 141).

\section{Metodologia e definição da amostra}

A metodologia empregada, como referida, seguiu os critérios adotados em parte do estudo que aqui replicamos, intitulado Algoritmos racistas: uma análise da hiper-ritualização da solidão da mulher negra em bancos de imagens digitais $^{6}$, ressalvadas algumas adaptações ao nosso foco privilegiado de análise. $\mathrm{O}$ estudo original dedicou-se à

5 É a tradução para Newsfeed, e refere-se à composição textual dinâmica que constitui a página inicial do usuário (JURNO, 2016). Trata-se da interface em que os usuários visualizam o conteúdo selecionado pelos algoritmos da plataforma entre postagens diversas (JURNO, Amanda Chevtchouk. (In)visibilidade algorítmica no "feed de notícias" do Facebook. Contemporânea: Comunicação e Cultura, v. 15, n. 2, pp. 463-484, mai./ago., 2017).

6 Trabalho realizado em 2019 por Fernanda Carrera e Denise Carvalho, e apresentado ao Grupo de Trabalho de Comunicação e Cibercultura do XXVIII Encontro Anual da Associação Nacional dos Programas de Pós-Graduação em Comunicação (Compós), da Pontifícia Universidade Católica do Rio Grande do Sul. Fernanda Carrera é Professora da Escola de Comunicação da Universidade Federal do Rio de Janeiro (UFRJ), professora do Programa de Pós-Graduação em Estudos da Mídia da Universidade Federal do Rio Grande do Norte (PpgEM/UFRN), doutora em Comunicação pela Universidade Federal Fluminense (UFF), e mestre em Comunicação e Cultura Contemporâneas pela Universidade Federal da Bahia (UFBA). Denise Carvalho é pós-doutoranda no Programa de Pós-Graduação em Estudos de Mídia (PpgEM/UFRN), doutora em Sociologia pela Universidade de São Paulo (FFLCH/USP) e mestre em Direito pela USP. 
análise do preterimento afetivo da mulher negra, expresso na hiper-ritualização ${ }^{7}$ do imaginário social sobre suas identidades através da circulação de imagens estereotipadas. Diante dessa temática, o estudo abordou de forma residual a hiper-ritualização da neutralidade e da universalidade da branquitude, aspecto que, aqui, tomamos como centralidade.

Assim, replicamos parcialmente a pesquisa em questão, tomando-a como modelo metodológico para a coleta dos dados, e adicionando ao processo de análise o elemento comparativo entre os resultados apresentados na pesquisa original e aqueles obtidos neste trabalho de pesquisa. Para tanto, foram analisados os mesmos bancos de imagens digitais examinados no estudo original. Da mesma forma, as palavras-chave utilizadas e os contextos visuais observados seguiram os mesmos critérios aplicados ao estudo de referência ${ }^{8}$. O objetivo foi o de verificar se houve mudanças significativas nos resultados produzidos para as mesmas condições de busca entre o período em que o estudo original foi realizado (primeiro semestre de 2019) e o período em que realizamos este (agosto de 2020) ${ }^{9}$.

Foram examinadas as três primeiras páginas de resultados para a busca pela expressão family ${ }^{10}$, utilizando-se o filtro padrão de cada site. A escolha por analisar os resultados para tal expressão corresponde ao intento de observar de que maneira os resultados são racializados pelo algoritmo de busca quando utilizada uma palavra-chave genérica. Assim, a análise baseou-se na identificação de imagens que correspondessem aos contextos visuais de famílias brancas, famílias negras, e famílias inter-raciais e de outras raças/etnias, com o objetivo de testar a hipótese de que a pesquisa pelo termo genérico family resultará em maioria de famílias brancas como representação imagética e algorítmica da hiper-ritualização da neutralidade da branquitude. Isso porque, ao não inserir as expressões White ou Black para caracterizar o termo family, o algoritmo entende que a pesquisa é "neutra", oferecendo resultados que entende como não racializados ("CARRERA, 2019).

Os bancos de imagens analisados foram o Getty Images ${ }^{11}$, o Shutterstock ${ }^{12}$, e o Stock Photos ${ }^{13}$, importantes fontes de recursos imagéticos no campo publicitário, comercial, jornalístico e governamental. Tal relevância justificou a escolha das pesquisadoras em analisá-los, bem como também a nossa em repetir o estudo. Além disso, chamounos especialmente a atenção o fato de que dois desses bancos de imagens (Getty Images e Shutterstock) incluíram, em suas páginas iniciais, campanhas relacionadas ao movimento Black Lives Matter ${ }^{14} \mathrm{e}$ à representatividade negra

7 O conceito de hiper-ritualização foi utilizado pelas autoras do estudo original como base analítica para o material coletado. Trata-se de um conceito de Erving Goffman (ano) que designa a representação de identidades em imagens publicitárias. Segundo Carrera e Carvalho, na obra Gender Advertisements, publicada em 1979, o autor analisou mais de 500 fotografias e ilustrações com o objetivo de apontar as representações de gênero reveladas por tais imagens publicitárias, o que chamou de hiper-ritualização de gênero. A pesquisa constatou que as mulheres costumam ser representadas em tamanho menor que os homens, mostradas como carentes de orientação e proteção masculina, associadas à fragilidade e infantilizadas. No entanto, a pesquisa realizada por Goffman negligenciou especificidades que poderiam trazer resultados diversos com a inserção de outras variáveis na análise, como raça, classe e contexto geográfico-cultural (Carrera e Carvalho, 2019). Fazendo um levantamento de pesquisas que empregaram o conceito do autor para analisar a representação de mulheres em outros contextos, as pesquisadoras puderam constatar que há diferenças consideráveis na forma como são representadas as mulheres negras e as mulheres brancas. As mulheres negras não são comumente associadas à fragilidade, mas à força e à selvageria, e costumam ser menos representadas na companhia de homens, aspecto que chamou a atenção das pesquisadoras em especial. Assim, empregaram o conceito de Goffman como base analítica para comparar a representação de mulheres brancas e negras em bancos de imagens digitais, com o objetivo de verificar se há diferenças nos resultados das buscas apresentados algoritmicamente. As autoras buscaram analisar especificamente a questão da independência/solidão no contexto familiar. Isso justifica a escolha das palavras-chave utilizadas para realizar a coleta de imagens (family, white family e black family), conforme veremos a seguir. Na primeira parte do trabalho, as pesquisadoras analisaram se as mulheres negras são apresentadas ao lado de homens na mesma proporção que as mulheres brancas. Em seguida, analisaram de que forma os resultados imagéticos sobre família e afetividade diferem e se assemelham aos resultados que mostram mulheres brancas. Assim, a pesquisa foi atravessada pela compreensão da série de fatores que podem influenciar a construção de estereótipos imagéticos - neste caso, revelados por algoritmos em bancos digitais -, como o preterimento da mulher negra e a neutralidade associada à branquitude, aspecto que, neste estudo, tomamos como objeto privilegiado de análise. Diante disso, cabe observar, utilizamos o conceito de hiper-ritualização de Goffman para sinalizar os resultados encontrados na pesquisa que realizamos. Assim, embora não estejamos partindo dele como base teórica para nossa problematização, o utilizamos como chave analítica e como indicador para as questões que buscamos pensar.

8 Tais critérios foram escolhidos pelas autoras do estudo original com o objetivo de verificar as hipóteses por elas levantadas segundo sua abordagem teórica, com a qual dialogamos, não em sua completude, mas em larga medida.

9 Importante frisar a esse respeito que, não sendo possível precisar se os algoritmos de busca dos bancos de imagens analisados levam em consideração critérios de personalização para a produção dos resultados, também não é possível afirmar que as diferenças entre os resultados comparados não se devem em alguma medida a diferenciações relacionadas a tais critérios. Em outras palavras, não é possível asseverar que, em algum grau, os resultados não sejam influenciados pelo "perfil" das pesquisadoras.

10 Utilizamos a mesma expressão utilizada para este fim no estudo replicado. Segundo as pesquisadoras, as palavras-chave escolhidas foram empregadas na língua inglesa como forma de tentar a generalização dos resultados dos bancos de imagens em questão - tendo em vista que estes são utilizados mundialmente -, embora se saiba que os sites são acionados de forma geolocalizada, reconhecendo o local de onde parte a busca. O banco de imagens Getty Images pode ser acessado através deste link: https://www.gettyimages.com.br/. Acesso em: 01/11/2020.

O banco de imagens Shutterstock pode ser acessado neste link: https://www.shutterstock.com/pt/. Acesso em: 01/11/2020.

O banco de imagens Stock Photos pode ser acessado neste link: https://stockphotos.com.br/. Acesso em: 01/11/2020.

14 Sobre o movimento que tem sua radicação nos EUA e elabora uma frente das estratégias dos movimentos negros estadunidenses, cf. TAYLOR, 2016. 
(respectivamente), instigando ainda mais nosso interesse em realizar a pesquisa. Assim, buscamos verificar se, de fato, tais campanhas refletiram efetivamente na modificação das representações discriminatórias em termos de raça nesses bancos de imagens, bem como analisar o modo como se propuseram a fazê-lo, e o impacto das medidas adotadas nos problemas apontados.

Ressalta-se que as imagens foram contabilizadas somente segundo as categorias elencadas, de modo que a soma entre as quantidades de imagens contabilizadas para cada categoria não corresponde à quantidade total de imagens analisadas. Isso devido a não compatibilidade de algumas imagens a nenhuma das categorias eleitas, não tendo sido, portanto, contabilizadas. Cabe também lembrar que, ao longo da análise, foram feitas observações referentes à identificação de outros padrões representacionais que chamaram nossa atenção. Essas observações foram pontuadas na análise dos resultados.

\section{Hipóteses e resultados}

A hipótese que conduziu a pesquisa de referência questiona se o termo genérico family resultaria em maioria de famílias brancas, tendo em vista que a tendência do algoritmo é entender que a pesquisa é "neutra" e oferecer os resultados que entende como não racializados, segundo um paradigma de universalização da branquitude. Tal resultado poderia ser tomado como evidência da hiper-ritualização imagética e algorítmica da branquitude enquanto padrão de representação que se traduz como significante universal.

Também os resultados do estudo original confirmaram a hipótese levantada pelas pesquisadoras para os três bancos de imagens selecionados. Da totalidade de 920 imagens analisadas, 543 representavam contextos visuais equivalentes a famílias totalmente brancas ( $58,05 \%$ da amostra). Apenas 58 imagens eram representativas de contextos visuais equivalentes a famílias totalmente negras $(6,30 \%$ da amostra), e 57 imagens de famílias inter-raciais e de outras raças/etnias $(6,19 \% \text { da amostra })^{15}$.

No banco de imagens Getty Images, das 300 imagens resultantes para a expressão family, 107 eram de famílias totalmente brancas, 24 eram de famílias totalmente negras, e 22 de famílias inter-raciais e de outras raças/etnias. Já no banco de imagens Shutterstock, das 319 imagens resultantes, 214 eram de famílias totalmente brancas, 20 eram de famílias totalmente negras, e 20 de famílias inter-raciais e de outras raças/etnias. Por fim, no banco Stock Photos de imagens, das 301 imagens resultantes para a expressão family, 213 eram de famílias totalmente brancas, 14 eram de famílias totalmente negras, e 15 de famílias inter-raciais e de outras raças/etnias.

Gráfico 1 - Resultados apresentados pela pesquisa original para o termo family

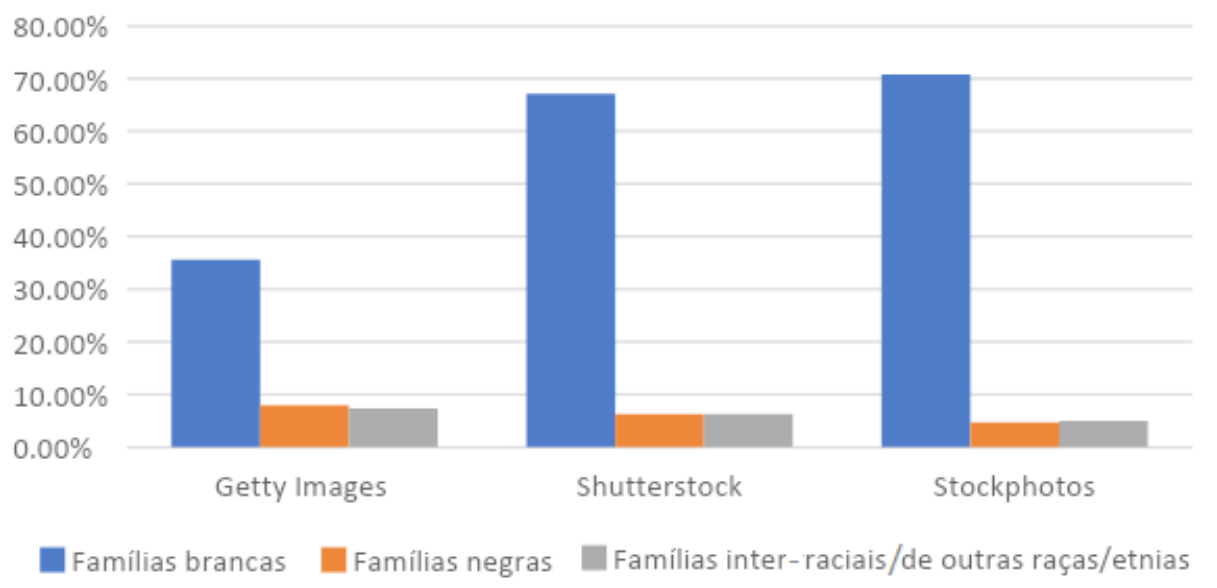

Fonte: elaboração própria (agosto de 2020).

15 Os outros $29,47 \%$ dos resultados não corresponderam a nenhuma das categorias analisadas. É o caso das fotografias ou ilustrações nas quais é impossível definir a raça dos participantes ou nas quais estão representados crianças ou adultos sozinhos, objetos, paisagens, entre outros. 


\subsection{Hipótese comparativa e elementos diferenciadores}

Diante dos resultados apresentados pela pesquisa original, replicamos a mesma metodologia para novo levantamento de dados, com o objetivo de realizar uma análise comparativa entre os resultados obtidos nos diferentes momentos de coleta. Assim, buscamos verificar se os resultados produzidos seguem comprometidos com o padrão de branquitude, segundo o qual o termo family deve corresponder a uma maioria significativa de imagens - já que a partir do contexto visual representa famílias totalmente brancas. Em especial, atentamos em nosso exercício comparativo para os resultados apresentados pelos bancos de imagens Getty Images e Shutterstock, que anunciaram em suas páginas iniciais campanhas indicando atenção às questões que envolvem a discriminação racial.

O banco de imagens Getty Images colocou em destaque em sua página inicial a seguinte mensagem em hiperlink: "Vidas negras importam. Nosso comprometimento com a mudança. Leia nosso esclarecimento na íntegra", cujo link relacionado ao texto levou a uma página veiculando a seguinte manifestação, datado de 18 de junho de 2020:

Vidas Negras Importam.

Na Getty Images, por muito tempo, vidas negras não importaram o suficiente e isso muda agora não podemos mais esperar. Por que esperamos para compartilhar uma declaração externa? É uma pergunta justa e aceitamos qualquer crítica pelo atraso. Não temos a diversidade e a inclusão que realmente aspiramos, especialmente em nossa liderança, e, por isso, demoramos um tempo para ouvir e entender melhor as experiências de nossos colegas negros, dentro e fora da Getty Images. Somos gratos por sua generosidade e coragem em compartilhar conosco suas experiências vividas. Nós os ouvimos; suas palavras direcionaram fundamentalmente nossa nova perspectiva, esta declaração e as ações que estamos descrevendo. A Getty Images se opõe ao racismo. A liberdade de imprensa é fundamental para a erradicação do racismo em todos os aspectos da sociedade. A Getty Images se opõe a restrições, intimidação e perseguição para limitar a liberdade de expressão, o direito de protestar e o direito da mídia de cobrir eventos com segurança, liberdade e imparcialidade. Reconhecemos plenamente que as palavras são apenas boas quando seguidas por mudanças reais que acontecem em nossa organização e em nossa indústria para enfatizar que as Vidas Negras Importam todos os dias.

Cultura e Representação.

Devemos basear a nossa cultura no antirracismo e na eliminação da supremacia branca. Isso significa promover um ambiente com oportunidades de oferecer feedback sem medo e que incentive os funcionários a avisar sobre comportamentos e ações contra negros. Nós nos comprometemos a prestar contas e a ter uma tolerância zero ao racismo em nosso ambiente de trabalho.

Devemos construir uma comunidade diversificada e criar um ambiente no qual todos possam prosperar. Como contratamos, desenvolvemos e compensamos em todos os níveis e em todos os departamentos, incluindo nossa rede global de criadores de conteúdo, deve ser corrigida quanto a esse desequilíbrio sistêmico. Nós nos comprometemos a mudar essa representação em todos os níveis de liderança.

Conteúdo.

Nós acreditamos que o poder das imagens pode mudar o mundo. Para fazer isso, precisamos apoiar criadores negros. Devemos contar mais histórias autênticas da comunidade negra global e reconhecemos novamente que não podemos fazer isso sem os criadores negros de conteúdo por trás das lentes. Juntamente com outras pessoas que estão criando, distribuindo e selecionando conteúdo visual, temos uma oportunidade urgente de promover mudanças positivas. Com essa mudança, nossa tecnologia deve apresentar conteúdo visual que reflete o mundo e nos comprometemos a continuar aprimorando a seleção e a pesquisa para remover preconceitos. Reconhecemos onde fracassamos no passado e nos comprometemos a fazer melhor. Somos responsáveis perante uns aos outros dentro da Getty Images, assim como perante os nossos clientes, criadores de conteúdo e parceiros. Entendemos que imagens têm o poder de mover o mundo e aceitamos a responsabilidade que vem com esse poder ${ }^{16}$.

Com essa manifestação, o banco de imagens Getty Images pareceu comprometer-se em promover medidas em pelo menos duas frentes para dirimir práticas racistas, reconhecendo a necessidade de uma cultura que parta de uma perspectiva antirracista: (i) representatividade na "comunidade" da empresa; (ii) aperfeiçoamento da

16 O texto está disponível em: http://press.gettyimages.com/vidas-negras-importam-pt/. Acesso em: 01/11/2020. 
tecnologia de seleção e de pesquisa de imagens para a produção de conteúdo visual que "reflita o mundo", e que conte as "histórias autênticas da comunidade negra global".

Por sua vez, o banco de imagens Shutterstock adicionou em sua página inicial a seguinte mensagem em hiperlink: "NOVIDADE: Um centro de recursos para representatividade negra. Obtenha conteúdo gratuito, além dos dados, novidades e ferramentas mais recentes para manter-se informado e disseminar sua mensagem. Veja só" (Figura 1).

Figura 1 - Print screen tirado do topo da página inicial do banco de imagens Shutterstock
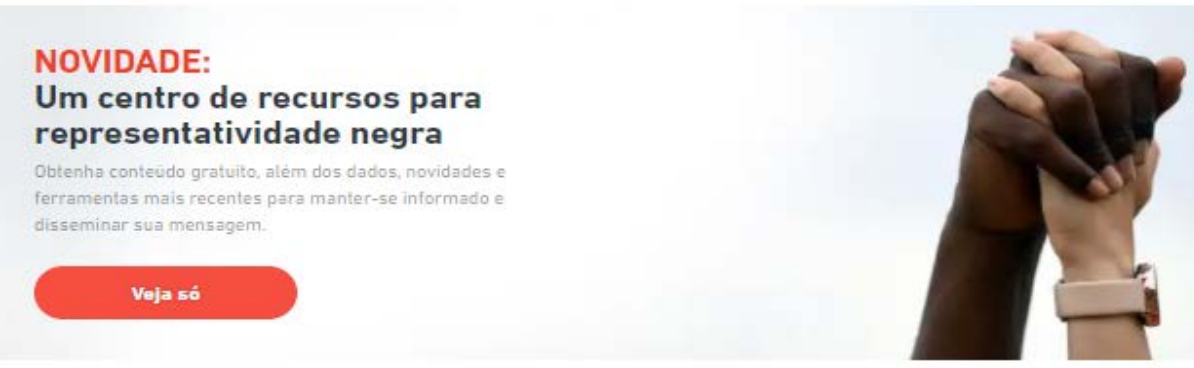

Fonte: Captura de tela em sua página digital. Elaboração própria (agosto de 2020). https://www.shutterstock.com/pt/.

O link relacionado ao texto levou a uma página veiculando o seguinte texto: "Representação negra no marketing e na mídia. Encontre o suporte e os recursos que você precisa para cobrir as últimas histórias e promover a representação negra em seus próximos projetos" (Figura 2).

Figura 2 - Print screen tirado da página do banco de imagens Shutterstock
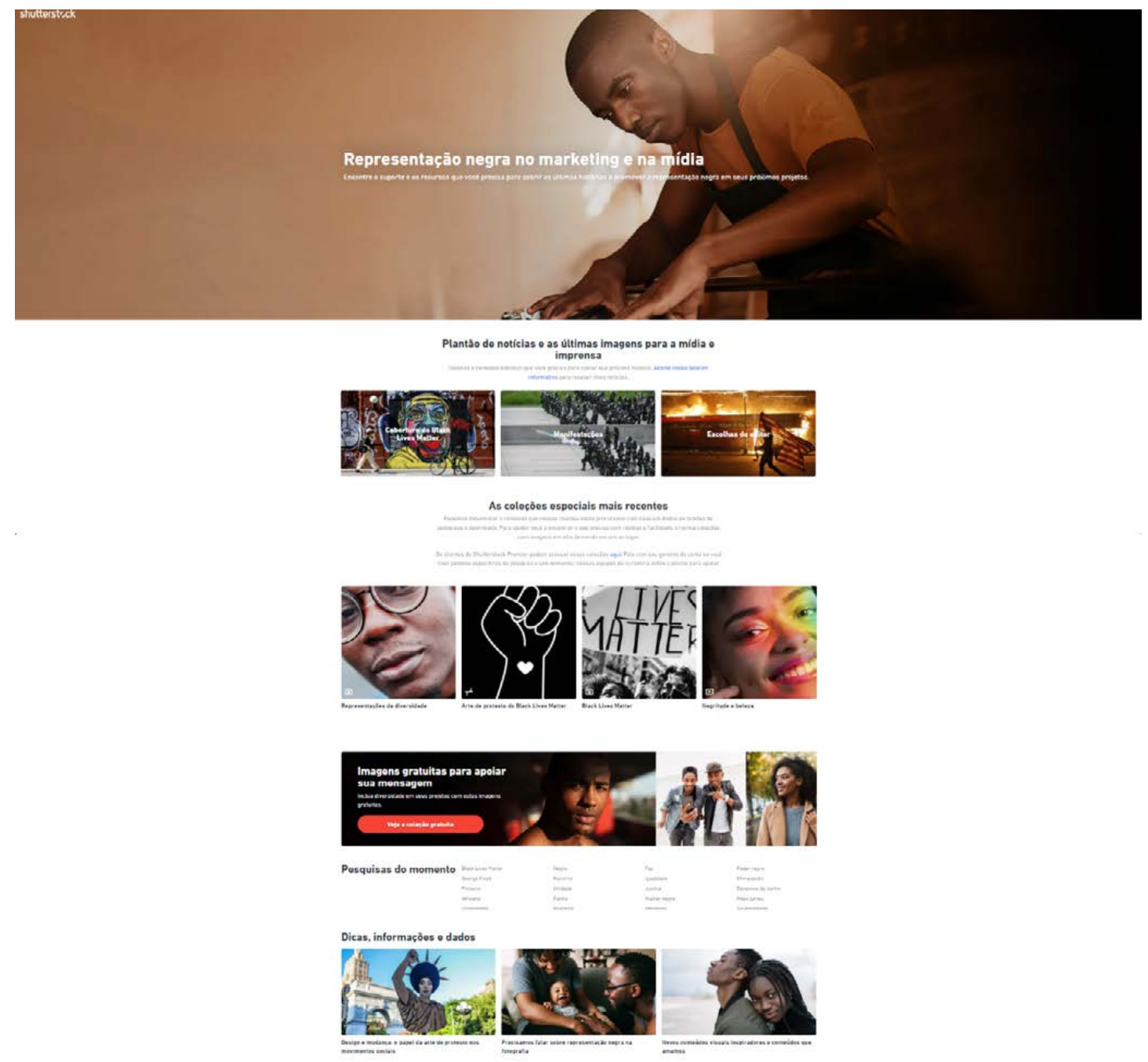

Fonte: Captura de tela em sua página digital. Elaboração própria (agosto de 2020). https://www.shutterstock.com/pt/featuredcollections/vetores-antirracismo-270916585. 
Conforme se vê na captura de tela acima (Figura 2), a página trouxe uma série de links para conteúdos editoriais de imagens relacionadas ao movimento Black Lives Matter em três categorias diferentes: Black Lives Matter; Demonstrators; Black Lives Matter, editors' picks. Mais abaixo, outros quatro links para As coleções especiais mais recentes: "Representações da diversidade; Arte de protesto do Black Lives Matter, Black Lives Matter; Negritude e beleza. Ainda mais abaixo, a página veiculou links para conteúdo visual relacionado ao que identifica como "diversidade": "Imagens gratuitas para apoiar sua mensagem. Inclua diversidade em seus projetos com estas imagens gratuitas. Veja a coleção gratuita" (Figura 2).

Na penúltima sessão da página, encontramos uma lista de links com as "Pesquisas do momento": Black Lives Matter, George Floyd, protesto, africano, diversidade, negro, racismo, unidade, punho, mudança, paz, igualdade, justiça, mulher negra, protestos, poder negro, Minneapolis, dezenove de junho, mãos juntas, solidariedade. Por fim, na última sessão, encontramos dicas, informações e dados com links direcionados para três reportagens: Design e mudança: o papel da arte de protesto nos movimentos sociais, Precisamos falar sobre representação negra na fotografia e Novos conteúdos visuais inspiradores e conteúdos que amamos (Figura 2).

Diante da publicação de tais conteúdos, é possível perceber diferenças na forma de tratar a questão por cada um dos bancos de imagens. O texto publicado pelo banco de imagens Getty Images parece reconhecer que a questão racial atravessa as práticas da empresa transversalmente, assumindo, em alguma medida, a responsabilidade em empenhar esforços para modificar políticas e práticas racistas em diversos aspectos; desde a contratação do corpo de profissionais, passando pela experiência cotidiana do ambiente de trabalho, até chegar à produção de seu conteúdo visual. Já o conteúdo publicado pelo banco de imagens Shutterstock, parece compreender a questão racial como um elemento apartado das práticas e políticas da empresa, tratando-a como um elemento à parte da produção de conteúdo visual do site, isto é, oferecendo o conteúdo voltado à "diversidade" e à "representatividade negra" como um produto direcionado apenas aos potenciais clientes interessados.

Diante disso, buscamos identificar se, nesses bancos de imagens, a veiculação de um conteúdo pretensamente comprometido com práticas antirracistas de fato tem relação com a produção de resultados mais diversificados em termos de representação imagética e algorítmica - entre famílias brancas, negras, inter-raciais ou de outras raças/etnias - na busca pela palavra-chave genérica family. Assim, ao analisar os resultados obtidos na pesquisa, atentamos especialmente a esse aspecto, buscando verificá-lo comparativamente em relação aos resultados apresentados pela pesquisa original, bem como entre os novos resultados para cada banco de imagens.

\subsubsection{Resultados obtidos na replicação da pesquisa}

No banco de imagens Getty Images, das 300 imagens analisadas para a palavra-chave family, 73 eram de famílias totalmente brancas, 72 eram de famílias totalmente negras, e 49 eram de famílias inter-raciais e de outras raças/etnias. Já no banco de imagens Shutterstock, das 314 imagens analisadas, 191 eram de famílias totalmente brancas, 33 eram de famílias totalmente negras, e 25 eram de famílias inter-raciais e de outras raças/etnias ${ }^{17}$. Por fim, no banco de imagens Stock Photos, das 300 imagens analisadas, 185 eram de famílias totalmente brancas, 52 eram de famílias totalmente negras, e 15 eram de famílias inter-raciais e de outras raças/etnias.

7 Vale observar que não foram contabilizados os desenhos gráficos representativos de famílias. No entanto, durante o processo de contagem, foi possível observar grande presença dessas figuras representativas de famílias que puderam ser identificadas como representações de pessoas de pele branca. Comparativamente, poucas figuras representavam pessoas de pele negra. Isso significa que, se fossem contabilizadas tais imagens digitais, possivelmente os números seriam ainda mais discrepantes. 
Gráfico 2 - Resultados obtidos para o termo family

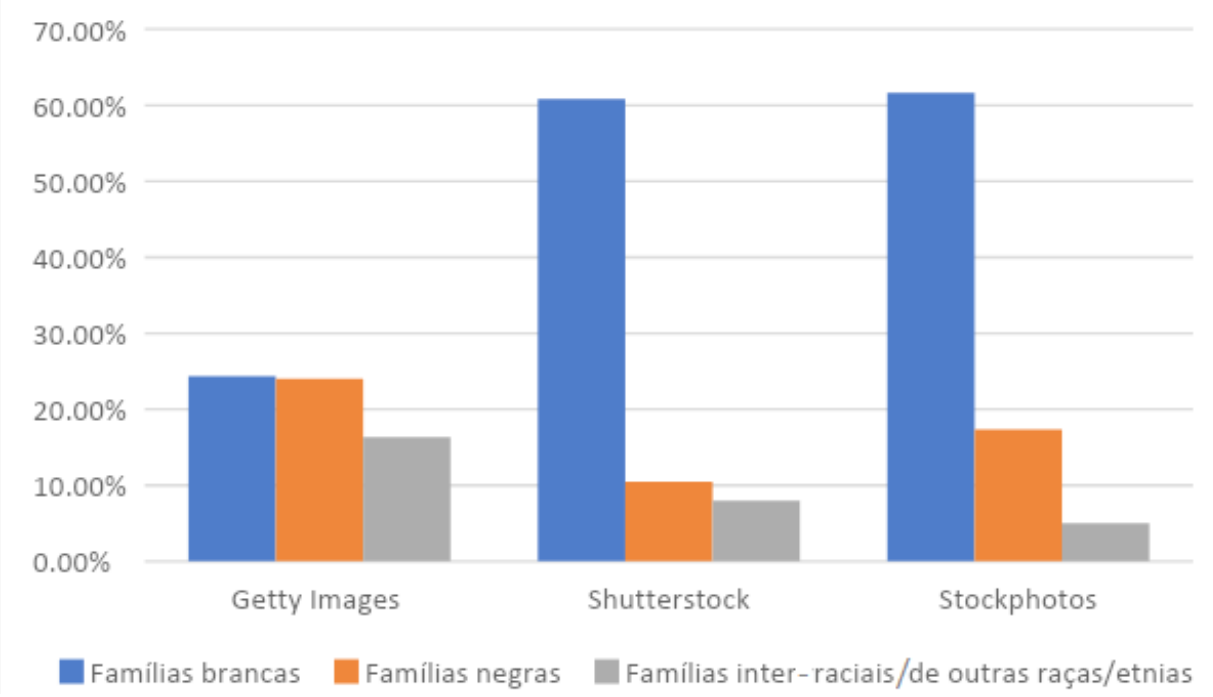

Fonte: elaboração própria (agosto de 2020).

\subsubsection{Análise dos resultados obtidos}

Com relação ao banco de imagens Getty Images, podemos perceber que houve mudanças significativas nos resultados produzidos para a busca pelo termo genérico family. Em comparação com os demais bancos de imagens, pode-se dizer que o Getty Images apresentou resultados consideravelmente mais plurais. Já com relação aos bancos de imagens Shutterstock e Stockphotos, podemos perceber que os resultados oferecidos seguem reproduzindo a hiper-ritualização da branquitude como padrão de representação universal, não racializada e neutra. Além disso, durante o processo de pesquisa, pudemos perceber um padrão pouco diversificado de imagens representativas de contextos sociais, paisagens e formações familiares muito semelhantes. Geralmente são representadas famílias heterossexuais formadas por casais jovens e sorridentes em ambientes saudáveis como casas bem ornamentadas ou jardins ensolarados.

Assim, entre os bancos de imagens que pareceram comprometer-se em estar atentos às questões raciais na produção de conteúdo visual, somente o Getty Images realizou medidas com impacto na hiper-ritualização da branquitude como padrão de representação imagética e algorítmica. Em comparação com os resultados oferecidos pelo mesmo banco de imagens na pesquisa anterior, é possível perceber uma diferença considerável para o aspecto em questão.

Gráfico 3 - Comparação resultados Getty Images (2019 e 2020)

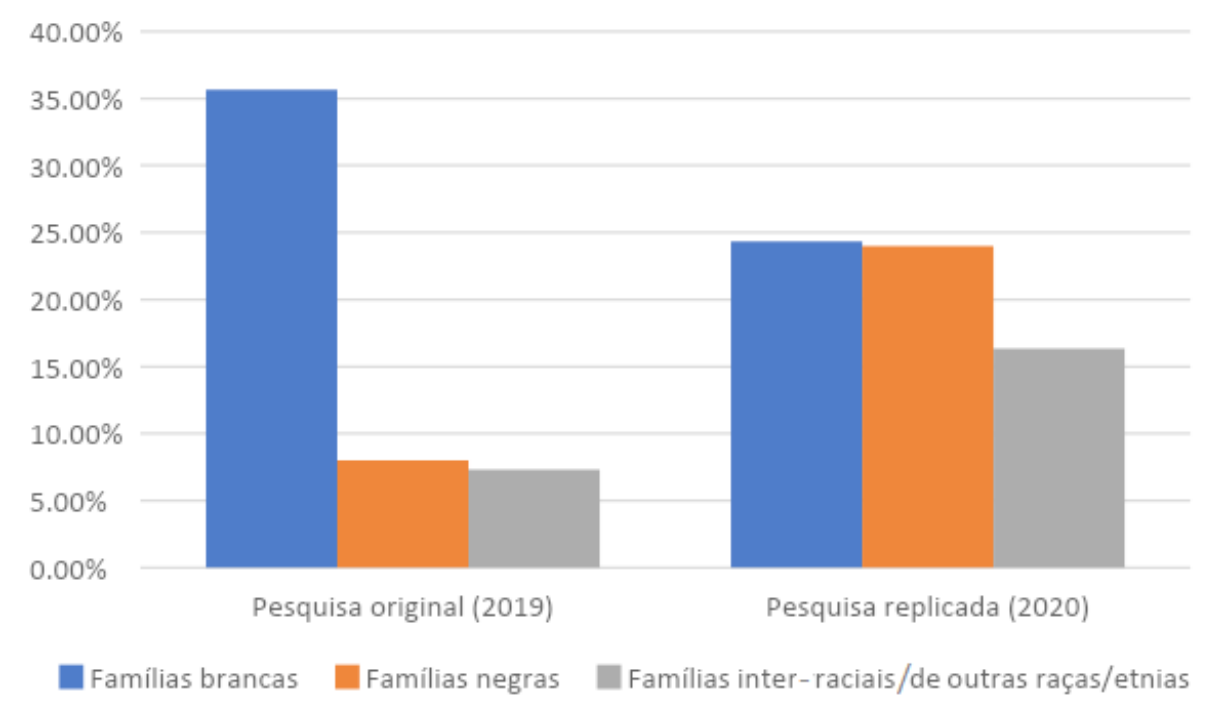

Fonte: elaboração própria (agosto de 2020). 
Cabe destacar que há um histórico de estudos e de críticas insistentes em apontar as problemáticas expressas nos resultados gerados por esse banco de imagens, assim como aos demais (AIELLO, 2016; AIELLO, 2013; AIELLO, 017; AIELLO, 2012; AIELLO e WOODHOUSE, 2016). Diversos desses estudos constatam que os resultados gerados pelo Getty Images costumam reafirmar estereótipos bastante marcados nos mais diversos âmbitos de representação. Nesse contexto, Fernanda Carrera lembra que o Getty Images se exime em seus termos de uso da responsabilidade "pelo conteúdo ou pela disponibilidade de informações contidas no seu diretório ou índice de pesquisa", bem como "pela integridade ou exatidão de qualquer diretório ou resultado de pesquisa" (CARRERA, 2020, p. 141). A pesquisadora assinala que tal manifestação de isenção de responsabilidade se deve também ao recente crescimento de acusações sobre seu potencial discriminatório (CARRERA, 2020, p. 142).

No mesmo sentido, possivelmente em resposta a críticas, o Getty Images, em associação com a Dove e a Girlgaze, lançou o projeto \#ShowUs (\#NosMostre), em que construiu "uma coleção específica de imagens mais diversas ao público feminino e não-binário, deixando claro que se trata de uma biblioteca de fotografias criada para o projeto, tagueada com palavra-chave especial a ele associada" (CARRERA, 2020, p. 142). Segundo Fernanda Carrera, tais medidas não expressam uma tentativa de transformar o desenho do site para que os resultados gerados sejam mais responsáveis em termos representacionais, mas apenas criam a impressão de que os sites são inclusivos, na medida em que expressam uma suposta intencionalidade de desafiar os estereótipos de gênero e raça. No entanto, se as imagens não compõem o universo da biblioteca, não é possível construir, de fato, uma composição igualitária de representação.

Por sua vez, o banco de imagens Shutterstock não apresentou alterações significativas com relação à hiperritualização da branquitude como padrão de representação imagética e algorítmica, apesar de ter incluído em seu site uma página dedicada a direcionar conteúdos relativos à representatividade negra. Assim, em comparação com os resultados oferecidos pelo mesmo banco de imagens na pesquisa anterior, é possível perceber que não há diferença significativa para o aspecto em questão.

Gráfico 4 - Comparação resultados Shutterstock (2019 e 2020)

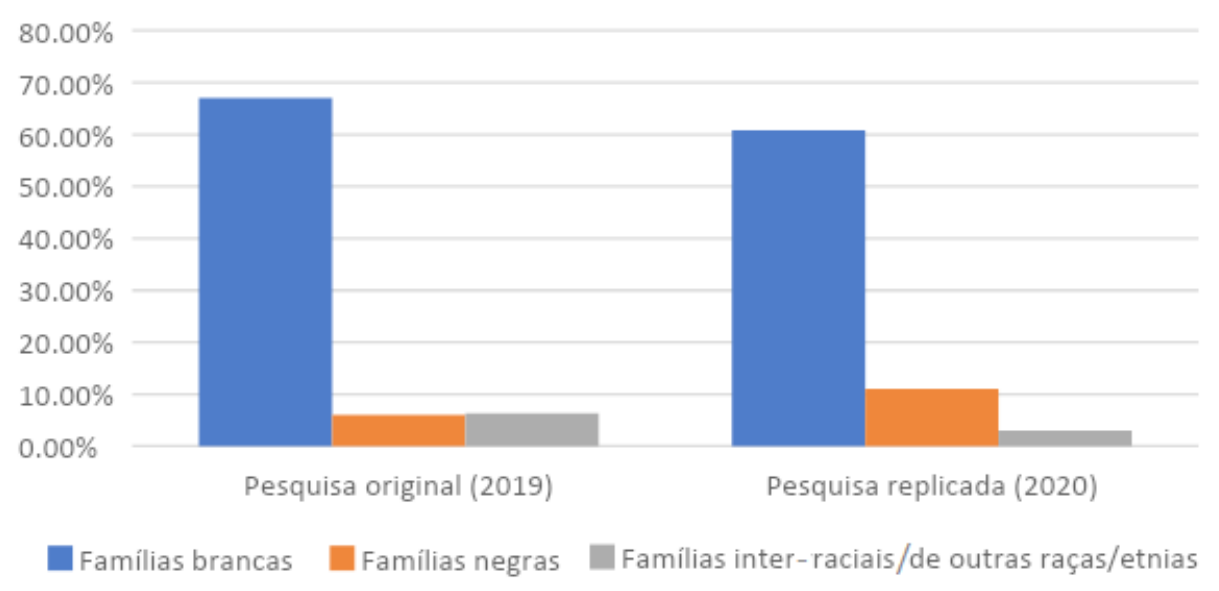

Fonte: elaboração própria (agosto de 2020).

Pode-se dizer que, no banco de imagens Getty Images, a inclusão de conteúdo autoproclamado antirracista no site de fato correspondeu a modificações significativas em suas práticas, ao menos no que diz respeito à produção de conteúdo visual mais plural e representativo da diversidade racial/étnica. Por outro lado, no banco de imagens Shutterstock, a inclusão de uma página no site veiculando conteúdo especial direcionado aos clientes interessados em "diversidade" e "representatividade negra" não correspondeu a modificações significativas. A diferença entre as políticas e práticas adotadas por cada um dos bancos de imagens, está na alteração ou na não alteração de seu algoritmo de busca.

Ao que tudo indica, o banco de imagens Getty Images promoveu alterações no processo de tagueamento das imagens e/ou no seu algoritmo de busca, produzindo resultados mais diversificados em termos raciais e étnicos para pesquisas por termos genéricos e "neutros" ou "não racializados". Nesse sentido, para além do que foi possível constatar, quantitativamente, pudemos observar, durante o processo de pesquisa, que o padrão representacional 
das imagens oferecidas por esse banco de imagens apresentou resultados notadamente mais diversificados, com a presença de fotografias de contextos sociais, paisagens e formações familiares distintos.

Figura 3 - Print screen tirado do topo da primeira página de resultados do banco de imagens Getty Images para o termo family

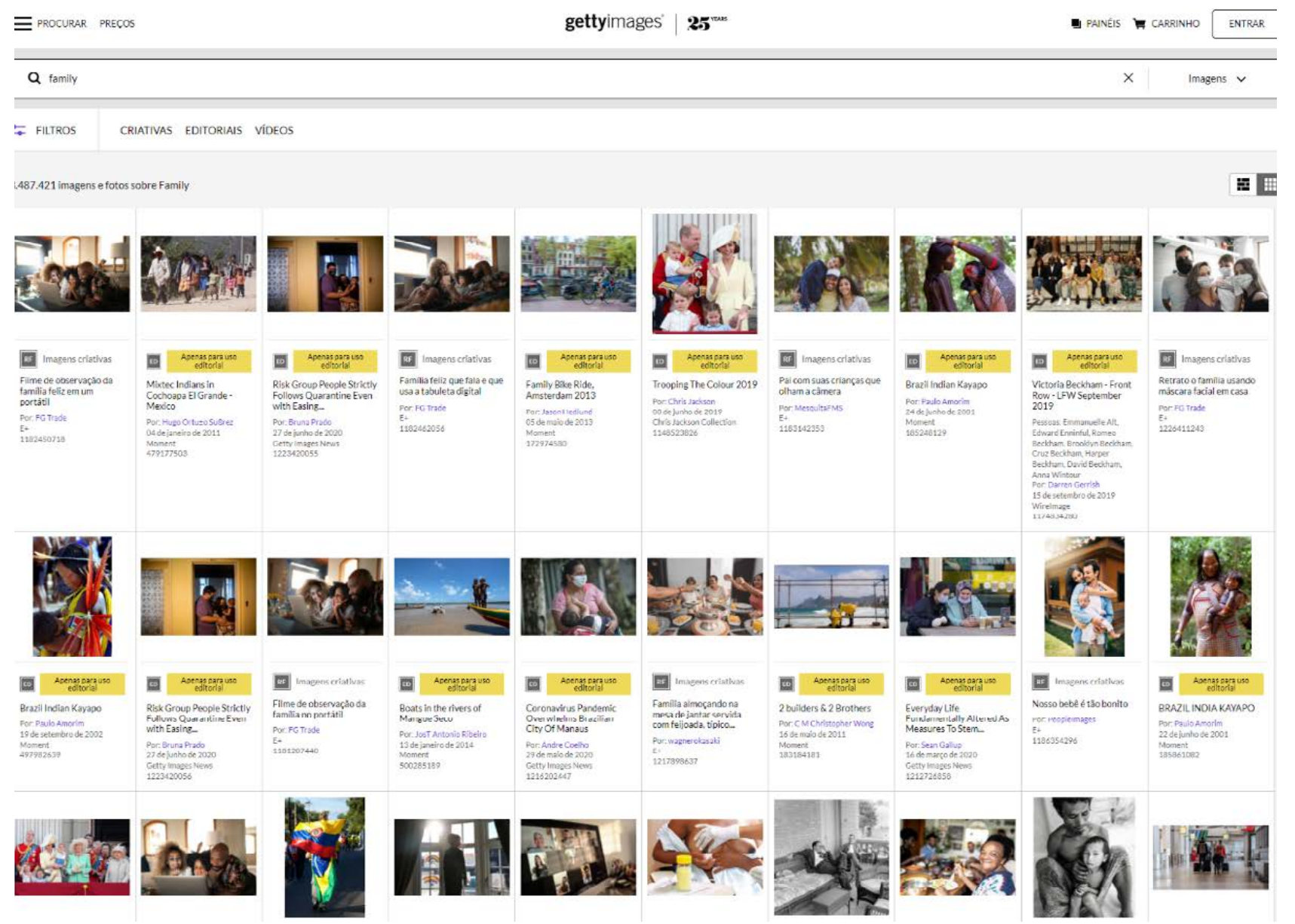

Fonte: Captura de tela em sua página digital. Elaboração própria (agosto de 2020): https://www.gettyimages.com.br/search/2/ image?family=creative\&phrase=family.

Em contrapartida, o banco de imagens Shutterstock não parece ter feito qualquer tipo de alteração nesse sentido. A criação de uma coleção especial de imagens voltadas à "representatividade negra" e à "diversidade racial" não tem impactos significativos na hiper-ritualização da branquitude como padrão de neutralidade. Isso porque somente aqueles que já estão em busca de conteúdo voltado à diversidade racial e à representatividade negra acessarão as imagens disponibilizadas. No entanto, para quaisquer outras buscas genéricas, o banco de imagens oferece resultados que reproduzem o padrão de branquitude.

Da mesma forma, em 2017, quando questionado a respeito dos resultados produzidos por seu algoritmo de pesquisa em um vídeo intitulado Vamos conversar, Shutterstock? ${ }^{18}$, o banco de imagens respondeu inserindo filtros étnicos em sua busca, mas não apresentou quaisquer alterações significativas nos resultados para termos genéricos, tampouco no padrão de imagens oferecidas. Os filtros acrescentados na barra lateral da página de buscas do site incluem as seguintes "categorias" de imagens: africana, afro-americana, negra, brasileira, caucasiana, chinesa, do leste da Ásia, hispânica, japonesa, do Oriente Médio, indígena norte-americana, das Ilhas do Pacífico, asiático do sul, do sudeste da Ásia, outra.

18 O vídeo foi produzido pela organização Desabafo Social e pode ser encontrado neste link: https://www.youtube.com/watch?v=tA7MIICbq00\&feature =youtu.be. Acesso em: 01/11/2020. A Desabafo Social é uma organização brasileira realizadora de projetos de empreendedorismo social, formação e produção de conteúdo, utilizando comunicação e novas tecnologias para promover educação em direitos humanos. Sobre a organização: www. desabafosocial.com.br.Acesso em: 01/11/2020. 
No entanto, ao experimentar a aplicação desses filtros, pudemos constatar que não há alterações no padrão representacional do repertório de imagens oferecidas. O contexto visual e estético das imagens apresentadas corresponde a um padrão cultural ocidentalizado, mesmo quando nela figuram personagens racializados pelo algoritmo de busca. Um bom exemplo disso apresenta-se a partir dos resultados obtidos quando aplicados os filtros africana, Afro-americana e negra, para a palavra-chave family. A aplicação do filtro africana não apresentou imagens que remetessem a contextos visuais relacionados à cultura africana, ao contrário do que se poderia supor hipoteticamente. Da mesma forma, a aplicação dos filtros afro-americana e negra para a mesma busca apresentou resultados representativos de contextos culturais muito semelhantes.

Figura 4 - Print screen tirado do topo da primeira página de resultados do banco de imagens Shutterstock para o termo family com aplicação do filtro étnico africana

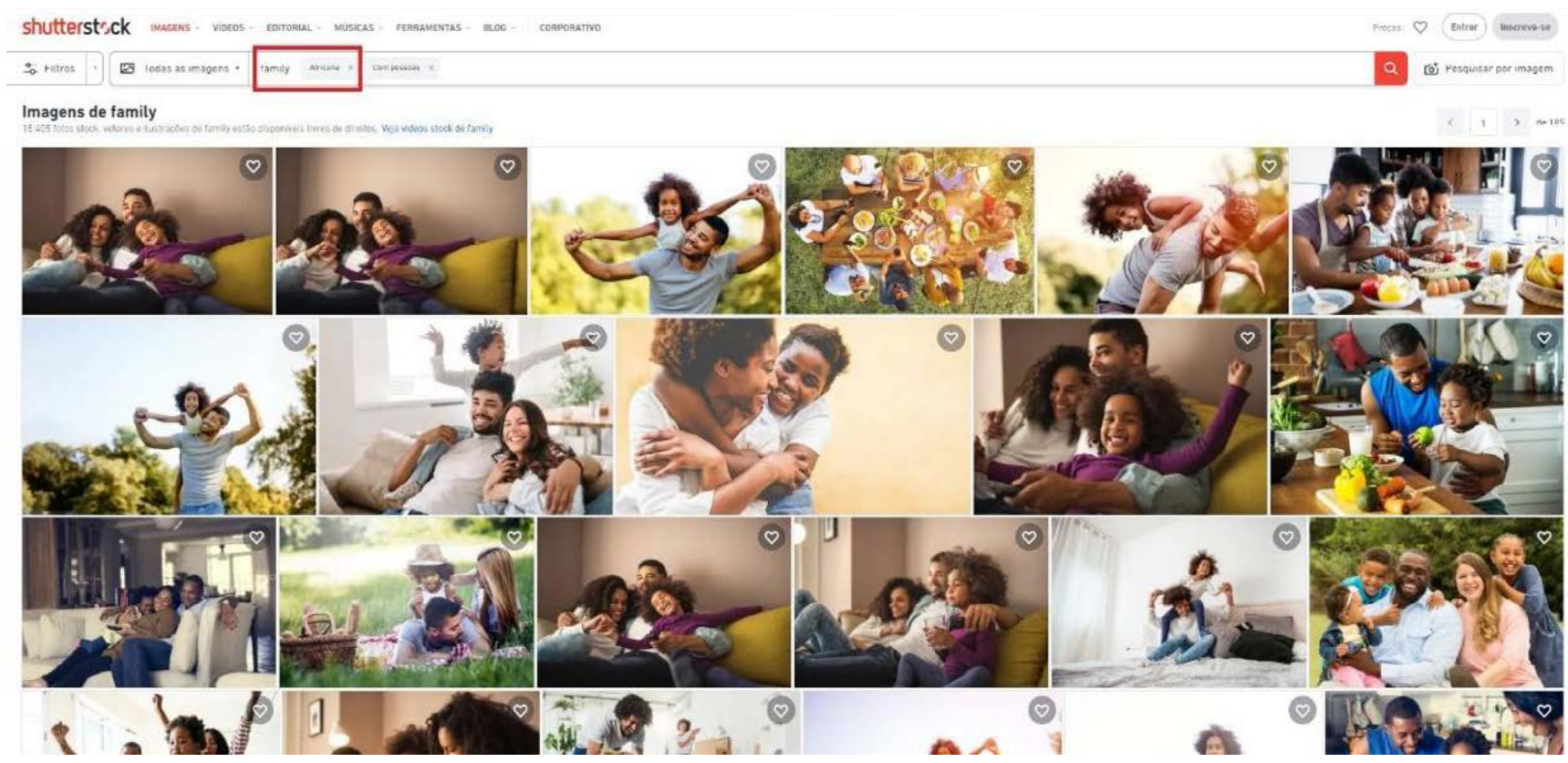

Fonte: Captura de tela em sua página digital. Elaboração própria (agosto de 2020): https://www.shutterstock.com/pt/search/fa mily?ethnicity=african\&mreleased=true.

Figura 5 - Print screen tirado do topo da primeira página de resultados do banco de imagens Shutterstock para o termo family com aplicação do filtro étnico afro-americana

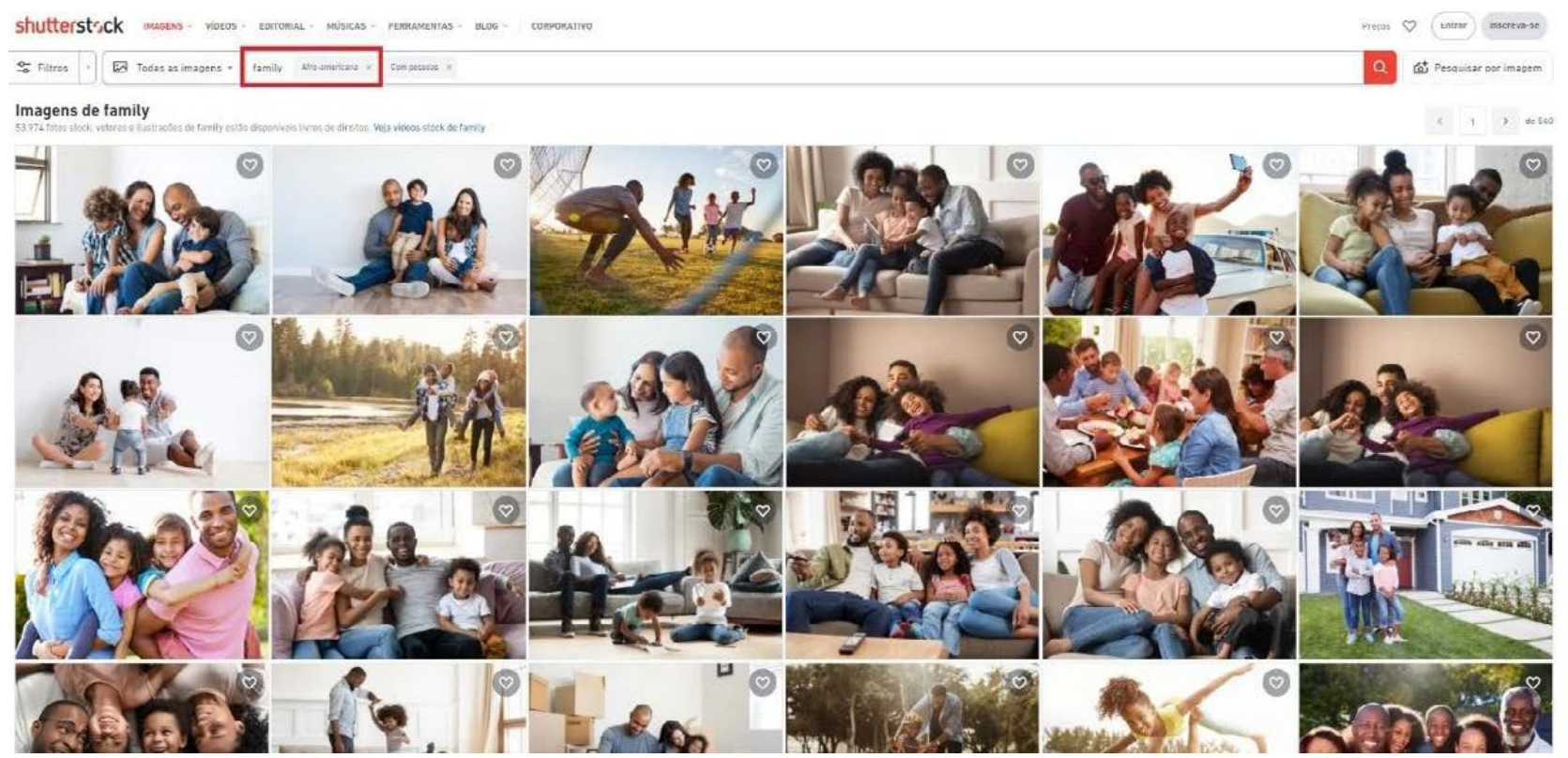

Fonte: Captura de tela em sua página digital. Elaboração própria (agosto de 2020): https://www.shutterstock.com/pt/search/ family?ethnicity=african_american\&mreleased=true. 
Figura 6 - Print screen tirado do topo da primeira página de resultados do banco de imagens Shutterstock para o termo family com aplicação do filtro étnico negra

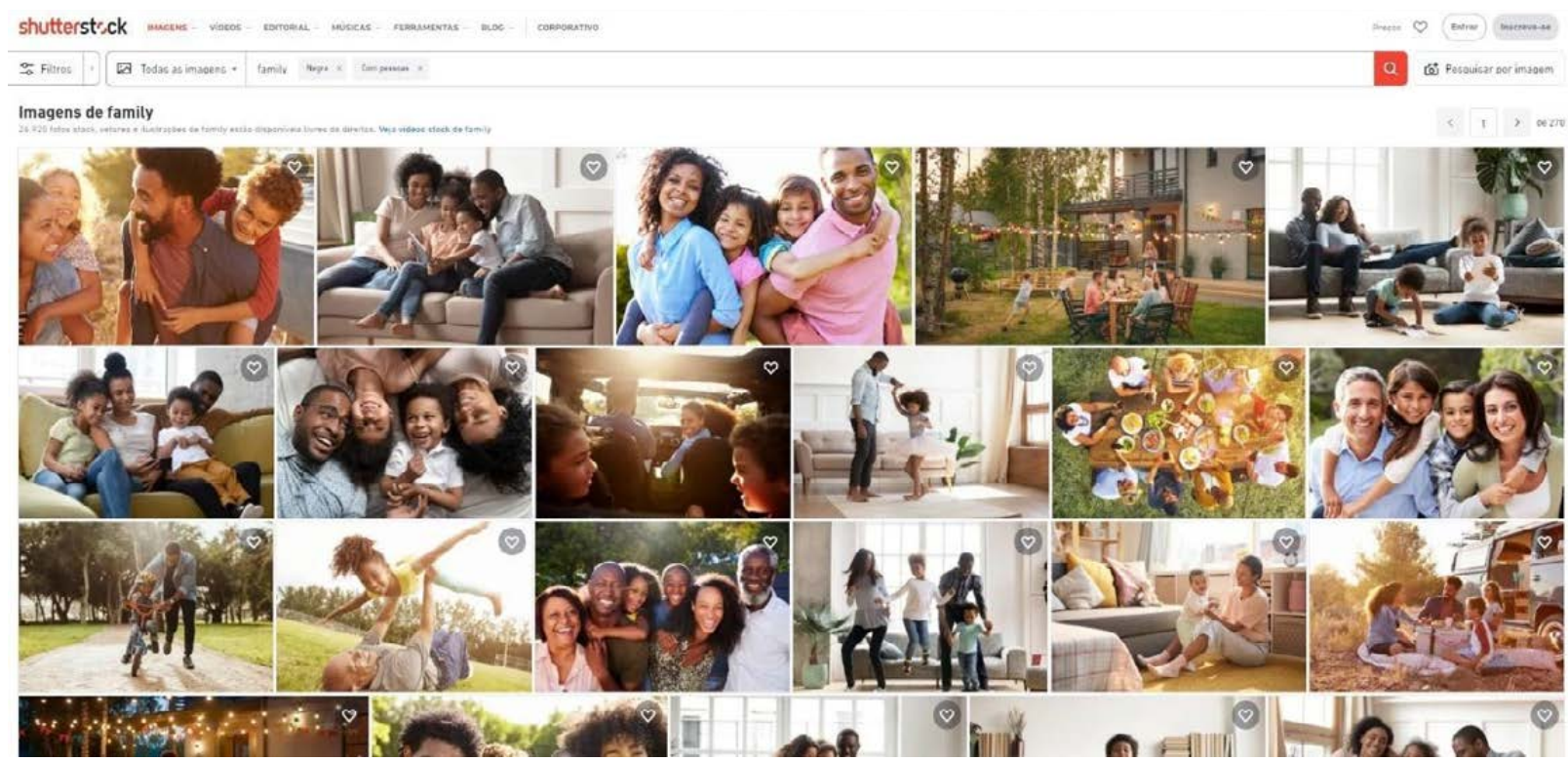

Fonte: Captura de tela em sua página digital. Elaboração própria (agosto de 2020): https://www.shutterstock.com/pt/search/fa mily?ethnicity=black\&mreleased=true.

Filtros "étnicos" semelhantes foram identificados no banco de imagens Getty Images, correspondendo às seguintes "categorias étnicas": Ásia Oriental, sudeste asiático, sul da Ásia, negro, hispânico/latino, caucasiano, Oriente Médio, nativo americano, Ilhas do Pacífico, multirracial, grupo multiétnico. Aplicamos o filtro negro à busca pela expressão family, e os resultados apresentaram imagens em contextos visuais diversos, confirmando novamente a constatação de que esse banco de imagens modificou sua produção de conteúdo visual em termos de diversidade.

Figura 7 - Print Screen tirado do topo da primeira página de resultados do banco de imagens Getty Images para o termo family com aplicação do filtro étnico negro

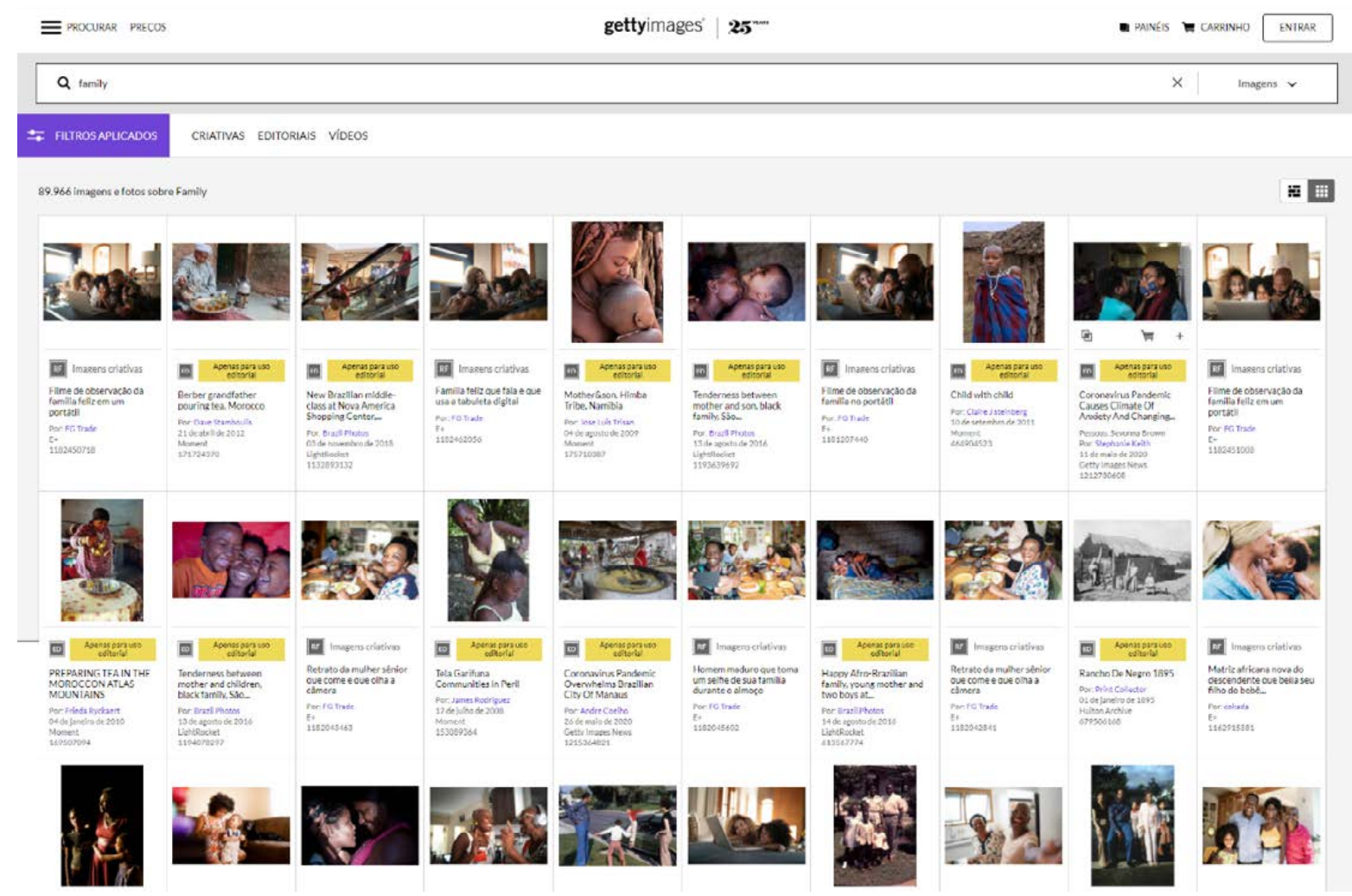

Fonte: Captura de tela em sua página digital. Elaboração própria (agosto de 2020): https://www.gettyimages.com.br/fotos/family? assettype=image\&license=rf\&alloweduse=availableforalluses\&family=creative\&phrase=family\&sort=mostpopular\&ethnicity=black. 
De acordo com Fernanda Carrera, tais iniciativas não expressam uma tentativa de transformar o desenho tecnológico do site para que as imagens postas em circulação correspondam às necessidades de representação diversificada e plural, mas criam um dispositivo de busca deslocado do todo imagético padronizado, com imagens que não compõem o universo de conteúdo disponibilizado como geral, comum, "neutro" (CARRERA, 2020, p. 140). No entanto, se as imagens não se misturam às outras imagens em pesquisas genéricas, não há uma construção igualitária de representação da diferença.

Por fim, cabe lembrar que o banco de imagens Stock Photos não fez qualquer alusão a questões étnicoraciais em sua página inicial. Ademais, pelo que se pode constatar explorando o site, além de os resultados oferecidos para a busca pelo termo genérico family serem representativos da hiper-ritualização da branquitude como padrão universal de neutralidade, o aparecimento de alguns padrões de imagens na representação de pessoas negras chamou a atenção das pesquisadoras, como a representação de famílias ou casais negros em situações negativas, como brigas. Tais representações foram identificadas em quantidade significativamente mais expressiva que famílias ou casais de pessoas brancas na mesma situação.

\section{Conclusão}

Nas atuais sociedades de controle, os algoritmos gerenciam antecipadamente o governo de populações, bloqueando ou permitindo a coleta ou exposição de informações pessoais valiosas para fins de segurança ou de produção. Administração daqueles que são pobres demais para a dívida e numerosos demais para o confinamento. Isso permite constatar que os dispositivos digitais não são apenas locais universais de acesso, tampouco são disponibilizados de forma igualitária. Ao contrário, estão inseridos em relações de poder que criam condições de exposição desigual a situações discriminatórias.

Conferir sentido a essa compreensão passa por perceber que tal distribuição é assinalada por inúmeros marcadores entre os quais raça, classe e gênero são alguns exemplos. Tal constatação implica perceber que o que está em jogo é o empreendimento de uma captura da multiplicidade que se propõe traduzir as mais variadas existências e relações humanas em uma expectativa de mandato de gênero, sexualidade, raça, entre outros delineadores normativos de subjetividade. Urgência esta que impinge não só compreender tais práticas, mas "tomar posição" (AMARAL, 2020) diante dos índices de alojamento das novas formas de governação das condutas.

Neste trabalho, buscamos explorar a temática dos algoritmos em dispositivos computo-informacionais, com o intuito de compreender de que maneira tais tecnologias produzem resultados discriminatórios. Entendendo que esses dispositivos participam de um regime particular de governo das populações, privilegiamos um "recorte" racial, entendendo a branquitude como significante universal que predomina em detrimento da representação da multiplicidade racial, étnica e cultural.

Assim, a partir do estudo realizado, foi possível constatar que, de fato, os resultados apresentados pelos bancos de imagens analisados costumam ser racializados privilegiando a centralização da branquitude como universalidade, reduzindo a multiplicidade de subjetividades e existências à sua representação. Isso se expressa, sobretudo, nos resultados predominantemente representativos da branquitude para consultas por palavras-chave genéricas, que, em tese, não deveriam direcionar o predomínio de uma única expressão racial, étnica e cultural. Verificamos que o uso da palavra-chave family nos bancos de imagens analisados produziu como output um conjunto de materiais gráficos cujo contexto imagético é majoritariamente representativo de famílias brancas, salvo a exceção do banco de imagens Getty Images, que apresentou resultados mais igualitários, ao menos no aspecto analisado neste estudo.

Com relação ao banco de imagens Getty Images, percebemos que houve mudanças significativas nos resultados gerados para a busca pela palavra-chave family em comparação com os resultados obtidos em pesquisa semelhante realizada em 2019. O marco diferenciador entre esses resultados, segundo indicado pelo próprio site, é a preocupação em atender às necessidades de produção de um conteúdo mais diversificado e igualitário em termos de representação racial, em especial, as reivindicadas pelo movimento Black Lives Matter. O histórico de estudos dedicados a observar a produção de circulação de imagens no Getty Images indica a importância das críticas contundentes feitas aos repositórios de imagens. Assim, longe de pretender afirmar que o banco de imagens resolveu definitivamente a problemática da representação em seu mecanismo de funcionamento, indicamos apenas a constatação de que foi possível observar alguma melhora na produção de resultados, tendo em vista os limites do marco comparativo e do recorte adotado neste estudo. 
Nesse sentido, cabe assinalar que supostas alterações nos algoritmos e no processo de indexação e tagueamento das imagens possivelmente implicaram mudanças significativas na produção do conteúdo visual oferecido pelo banco de imagens em questão. Ao contrário, o lançamento de coleções especiais deslocadas do universo de material oferecido pelo site não produz impacto relevante para atender às necessidades representacionais colocadas. Isso porque o impacto desejado implica que buscas genéricas gerem resultados plurais, não estereotipados e igualitários em termos representacionais.

Contrastando tais diferenças entre as formas de cada um dos bancos de imagens lidarem com a demanda por resultados mais igualitários em termos raciais (alterações no desenho tecnológico do mecanismo de busca Getty Images - e ausência de tais alterações - Shutterstock e Stock Photos), há fortes indícios de que os algoritmos cumprem em larga medida um papel fundamental na produção de resultados enviesados. Por outro lado, podem ser também fundamentais ao propósito de diversificar o conteúdo visual dos bancos de imagens, neste caso, deslocando a branquitude de seu local de centralidade no âmbito da representação imagética.

Sobre esse aspecto, cabe lembrar que a mediação algorítmica coloca diversas problemáticas mais amplas, sobretudo quando pensamos no contexto de Big Data em que está inserida. Assim, seria absolutamente precipitado pretender constatar uma solução para a questão no sentido do que foi possível observar no âmbito deste estudo. Em outras palavras, é importante lembrar que a mediação algorítmica apresenta problemáticas inerentes ao seu funcionamento, que tendem a reproduzir, de uma forma ou de outra, os mesmos mecanismos de redução do múltiplo a significantes universais. Nesse sentido, é importante também não esquecer que a produção do conteúdo visual gerado pelos bancos de imagens analisados está subordinada às necessidades do mercado, voltada para a valorização capitalista. Assim, não nos parece exagero assinalar que as conquistas de mudanças significativas nesse âmbito devem-se à militância das pesquisas que insistem em apontar seus vieses.

Portanto, a emergência do que se pode chamar uma governamentalidade algorítmica convoca a urgência em analisar a administração de formas de vida. Pois, "se não há nem nunca houve um fora dos jogos de poder, muito menos isto pode se dar agora, quando seus algoritmos rastreiam ininterruptamente nossas existências" (CHIGNOLA, 2018, p. 262). Eis a tarefa irremediável deste tempo: atentarmos à implementação do que já não está em vias de ser implantado (DELEUZE, 1992, p. 225), mas que está na emergência dos dias.

\section{REFERÊNCIAS}

AIELLO, Giorgia et al. A critical genealogy of the Getty Images Lean In Collection: researching the feminist politics of stock photography across representation, circulation, and recontextualization. Digital Methods Initiative, Amsterdam, p. 11-15, jan. 2016. Disponível em: https://wiki.digitalmethods.net/Dmi/ WinterSchool2016CriticalGenealogyGettylmagesLeanIn. Acesso em: 06 out. 2020.

AIELLO, Giorgia. Generiche differenze: la comunicazione visiva della soggettività lesbica nell'archivio fotografico Getty Images. Studi Culturali, Amsterdam, ano 10, n. 3, p. 523-548, dez. 2013. Disponível em: https://ssrn.com/ abstract=2473602. Acesso em: 01 nov. 2021.

AIELLO, Giorgia et al. Taking stock: can news images be generic? Digital Methods Initiative, Amsterdam, 31 jul. 2017. Disponível em: https://wiki.digitalmethods.net/Dmi/TakingStock. Acesso em: 06 out. 2020.

AIELLO, Giorgia. The 'other' europeans: the semiotic imperative of style in Euro Visions by Magnum Photos. Visual Comunication, Newbury Park, v. 11, n. 1, p. 49-77, jan. 2012. DOI: https://doi. org/10.1177/1470357211424686. Disponível em: https://journals.sagepub.com/doi/10.1177/1470357211424686. Acesso em: 01 nov. 2021.

AIELLO, Giorgia; WOODHOUSE, Anna. When corporations come to define the visual politics of gender: the case of Getty Images. Journal of Language and Politics, Leeds, v. 15, n. 3, p. 351-366, 2016.

AMARAL, Augusto Jobim do. Biopolítica e biocapitalismo. In: AMARAL, Augusto Jobim do. Política da criminologia. São Paulo: Tirant lo Blanch, 2020. p. 103-163.

AMARAL, Augusto Jobim do. Política da criminologia. São Paulo: Tirant lo Blanch, 2020. 
BENTO, Maria Aparecida Silva. Branqueamento e branquitude no Brasil. In: CARONE, Iray; BENTO, Maria Aparecida Silva (coord.). Psicologia social do racismo: estudos sobre branquitude e branqueamento no Brasil. Rio de Janeiro: Vozes, 2002. p. 25-58.

BENTO, Maria Aparecida Silva. Pactos narcísicos no racismo: branquitude e poder nas organizações empresárias e no poder público. 2002. Tese (Doutorado em Psicologia) - Instituto de Psicologia da Universidade de São Paulo, Universidade de São Paulo, São Paulo, 2002. DOI: https://doi.org/10.11606/T.47.2019.tde18062019-181514. Disponível em: https://teses.usp.br/teses/disponiveis/47/47131/tde-18062019-181514/pt-br. php. Acesso em: 06 out. 2020.

BRUNO, Fernanda. Rastrear, classificar e performar. Ciência e Cultura, São Paulo, v. 68, n. 1, p. 34-38, jan./mar. 2016. Disponível em: http://cienciaecultura.bvs.br/scielo.php?script=sci_arttext\&pid =S0009-67252016000100012. Acesso em: 06 out. 2020.

CARRERA, Fernanda. Racismo e sexismo em bancos de imagens digitais: análise de resultados de busca e atribuição de relevância na dimensão financeira/profissional. In: SILVA, Tarcízio (org.). Comunidades, algoritmos e ativismos digitais: olhares afrodiaspóricos. São Paulo: Literarua, 2020. p. 138-155.

CARRERA, Fernanda; CARVALHO, Denise. Algoritmos racistas: uma análise de hiper-ritualização da solidão da mulher negra em bancos de imagens digitais. In: ENCONTRO ANUAL DA ASSOCIAÇÃO NACIONAL DOS PROGRAMAS DE PÓS-GRADUAÇÃO EM COMUNICAÇÃO (COMPÓS), 28, Porto Alegre, 2019. Anais Eletrônicos [...]. Campinas: Galoá, 2019. Disponível em: https://proceedings.science/compos-2019/papers/ algoritmos-racistas--uma-analise-da-hiper-ritualizacao-da-solidao-da-mulher-negra-em-bancos-de-imagensdigitais. Acesso em: 01 nov. 2019.

CHIGNOLA, Sandro. A toupeira e a serpente. Revista Direitos e Garantias Fundamentais, Vitória, v. 19, n. 3 , p. 239-269, set./dez. 2018. Disponível em: https://doi.org/10.18759/rdgf.v19i3.1599. Acesso em: 29 out. 2021.

COMITÊ INVISÍVEL. Aos nossos amigos. São Paulo: Edições Antipáticas, 2015.

CRENSHAW, Kimberlé Williams. Mapping the margins: intersectionality, identity politics, and violence against women of color. Stanford Law Review, California, v. 43, n. 6, p. 1241-1299, jul. 1991. DOI: https://doi.

org/10.2307/1229039. Disponível em: https://www.jstor.org/stable/1229039?origin=crossref. Acesso em: 01 nov. 2021.

CRENSHAW, Kimberlé Williams. Demarginalizing the intersection of race and sex: a black feminist critique of antidiscrimination doctrine, feminist theory and antiracist politics. The University of Chicago Legal Forum, Chicago, v. 1989, n. 1, p. 139-167, 1989. Disponível em: https://chicagounbound.uchicago.edu/uclf/vol1989/ iss1/8/. Acesso em: 01 nov. 2021.

DARDOT, Pierre; LAVAL, Christian. A nova razão do mundo: ensaio sobre a sociedade neoliberal. São Paulo: Boitempo, 2016.

DELEUZE, Gilles. Post-scriptum sobre sociedade de controle. In: DELEUZE, Gilles. Conversações. São Paulo: Ed. 34, 1992. p. 219-226.

DONEDA, Danilo Cesar Maganhoto et al. Considerações iniciais sobre inteligência artificial, ética e autonomia pessoal. Pensar Revista de Ciências Jurídicas e Sociais, Fortaleza, v. 23, n. 4, p. 1-17, out./dez. 2018. Disponível em: https://periodicos.unifor.br/rpen/article/view/8257. Acesso em: 01 nov. 2021.

DREYFUS, Hubert Lederer. What computers still can’t do. New York: Harper Collins, 1979.

FOUCAULT, Michel. Nascimento da biopolítica: curso dado no Collège de France (1978-1979). São Paulo: Martins Fontes, 2008.

FOUCAULT, Michel. Segurança, território, população: curso dado no Collège de France (1977-1978). São Paulo: Martins Fontes, 2008.

GILLESPIE, Tarleton. A relevância dos algoritmos. Parágrafo, São Paulo, v. 6, n. 1, p. 95-121, jan./abr. 2018. 
GOBBO, Beatrice et al. Interrogating Vision APIs: Data Sprint Report. Smart Data Sprint: beyond visible enaggement, Lisboa, 28 jan./1 feb. 2019. Disponível em: https://smart.inovamedialab.org/smart-2019/projectreports/interrogating-vision-apis/. Acesso em: 03 out. 2020.

JURNO, Amanda Chevtchouk. (In)visibilidade algorítmica no "feed de notícias" do Facebook. Contemporânea: Comunicação e Cultura, Salvador, v. 15, n. 2, p. 463-484, maio/ago. 2017. DOI: https://doi.org/10.9771/ contemporanea.v15i2.17796. Disponível em: https://periodicos.ufba.br/index.php/contemporaneaposcom/article/ view/17796. Acesso em: 01 nov. 2021.

JURNO, Amanda Chevtchouk. Agenciamentos coletivos e textualidades em rede no Facebook: uma exploração cartográfica. 2016. Dissertação (Mestrado em Comunicação Social) - Programa de Pós-Graduação em Comunicação Social, Universidade Federal de Minas Gerais, Belo Horizonte, 2016. Disponível em: http://hdl. handle.net/1843/BUBD-AFDKTG. Acesso em: 01 nov. 2021.

JURNO, Amanda Chevtchouk. Facebook e a plataformização do jornalismo: uma cartografia das disputas, parcerias e controvérsias entre 2014 e 2019. 2020. Tese (Doutorado em Comunicação Social) - Programa de Pós-Graduação em Comunicação Social, Universidade Federal de Minas Gerais, Belo Horizonte, 2020. Disponível em: https://repositorio.ufmg.br/handle/1843/33955. Acesso em: 01 nov. 2021.

JURNO, Amanda Chevtchouk. Questões e apontamentos para o estudo de algoritmos. Parágrafo, São Paulo, v. 6, n. 1, p. 17-29, jan./abr. 2018. Disponível em: https://revistaseletronicas.fiamfaam.br/index.php/recicofi/article/ view/709. Acesso em: 01 nov. 2021.

KILOMBA, Grada. Memórias da plantação: episódios de racismo cotidiano. Rio de Janeiro: Cobogó, 2020.

LATOUR, Bruno. Reagregando o social: uma introdução à Teoria do Ator-Rede. São Paulo: Edusc, 2012.

LATOUR, Bruno. Ciência em ação: como seguir cientistas e engenheiros sociedade afora. São Paulo: UNESP, 2000.

NOBLE, Safiya Umoja. A future for intersectional black feminist technology studies. Scholar and Feminist Online, New York, issue 13.3 - 14.1, 2016. Disponível em: https://sfonline.barnard.edu/traversing-technologies/ safiya-umoja-noble-a-future-for-intersectional-black-feminist-technology-studies/. Acesso em: 12 ago. 2020.

NOBLE, Safiya Umoja. Algorithms of oppression: how search engines reinforce racism. New York: New York University Press, 2018.

NOBLE, Sofiya Umoja. Google Search: hiper-visibility as a means of rendering black woman and girls invisible. InVisible Culture: an Eletronic Journal for Visual Culture, Rochester, v. 19, 29 out. 2013. Disponível em: http:// ivc.lib.rochester.edu/google-search-hyper-visibility-as-a-means-of-rendering-black-women-and-girls-invisible/. Acesso em: 04 out. 2020.

O'NEIL, Cathy. Weapons of math destruction: how big data increases inequality and threatens democracy. New York: Broadway Books, 2016.

PASQUALE, Frank. The black box society. Cambridge: Harvard University Press, 2015.

ROUVROY, Antoinette; BERNS, Thomas. Governamentalidade algorítmica e perspectivas de emancipação: o díspar como condição de individuação pela relação?. Revista Eco Pós: Tecnopolíticas e Vigilância, Rio de Janeiro, v. 18, n. 2, p. 36-56, 2015. Disponível em: https://doi.org/10.29146/eco-pos.v18i2.2662. Acesso em: 01 nov. 2021.

SILVA, Tarcízio. Visão computacional e racismo algorítmico: branquitude e opacidade no aprendizado de máquina. Revista da ABPN, Guarulhos, v. 12, n. 31, p. 428-448, dez. 2019/fev. 2020.

SILVA, Tarcízio et al. APIs de visão computacional: investigando mediações algorítmicas a partir de estudo de bancos de imagens. Logos: comunicação e universidade, Rio de Janeiro, v. 27, n. 1, p. 25-54, 2020.

TAYLOR, Keeanga-Yamahtta. From \#BlackLivesMatter to black liberation. Chicago: Haymarket Books, 2016.

Recebido em: 03.11.2020

Aceito em: 27.09.2021 